\title{
Dipropinonates of Sugar Alcohols as Water-Soluble, Non-Toxic CPAs for DMSO-Free Cell Cryopreservation
}

\author{
Department of Chemistry \\ University at Buffalo \\ The State University of New York, \\ Buffalo, New York 14260 \\ United States
}

Yulong Zhong, Jillian K. McGrath, and Bing Gong*

\section{Supporting Information}

$\begin{array}{ll}\text { I. Supporting Figures and Tables } & \text { S2 }\end{array}$

II. Experimental Section $\quad$ S4

$\begin{array}{ll}\text { III. } & \text { Synthesis and Characterization }\end{array}$ 


\section{Supporting Figures and Tables}

a)

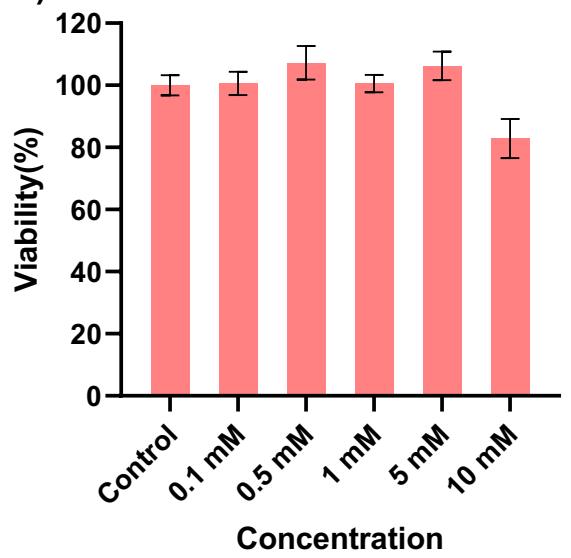

c)

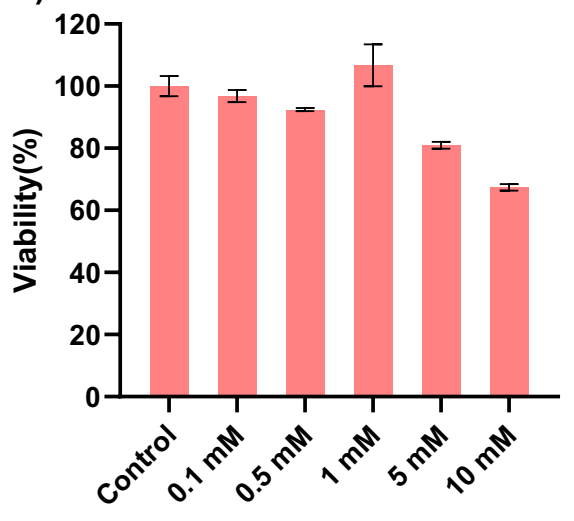

Concentration

e)

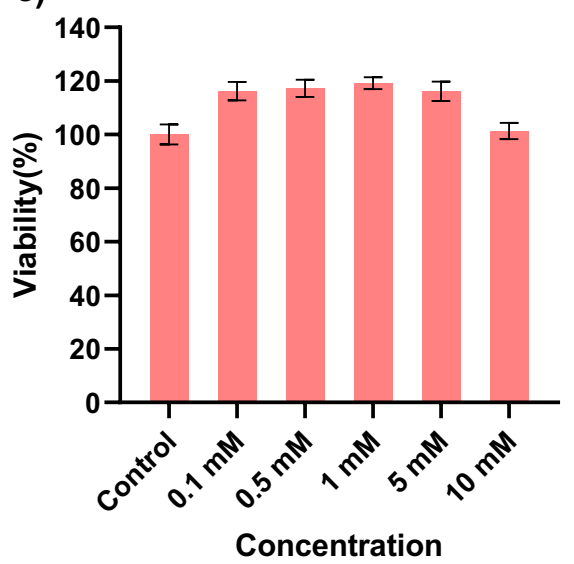

b)

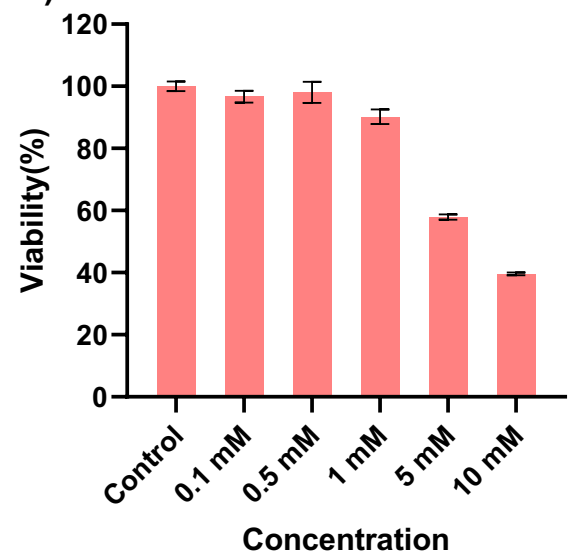

d)

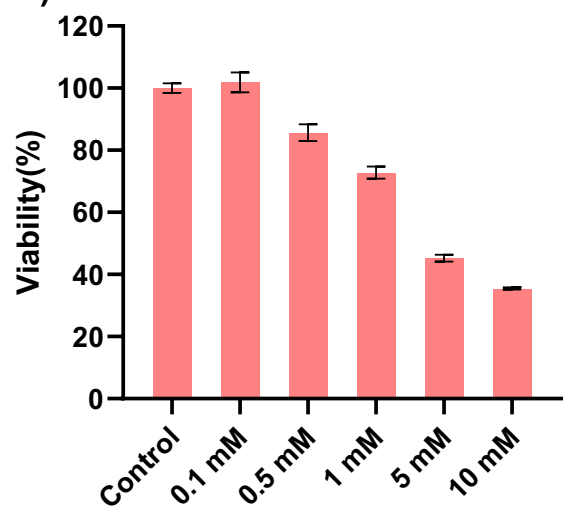

Concentration

f)

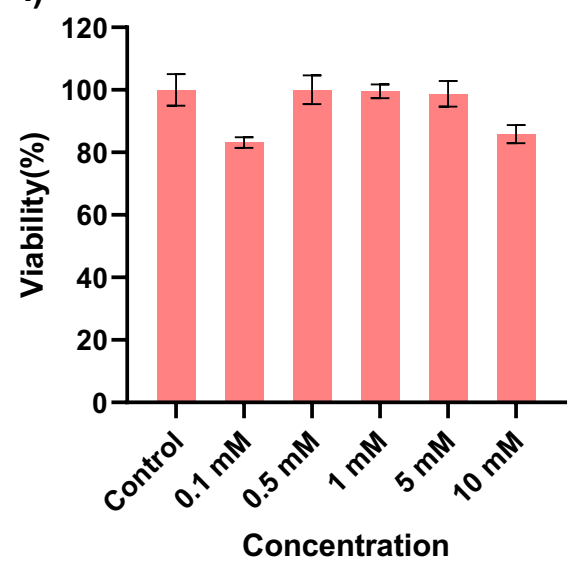

Figure S1. Cell viability after incubating with a) $\operatorname{SorbPr}_{2}(\mathbf{1})$, b) $\operatorname{SorbBa}_{2}(\mathbf{1 a})$, c) $\operatorname{MannPr}_{2}(2)$, d) $\mathrm{MannBa}_{2}$ (2a), e) XylPr 2 (3), f) EryPr 2 (4) for 48 hours. 
a)

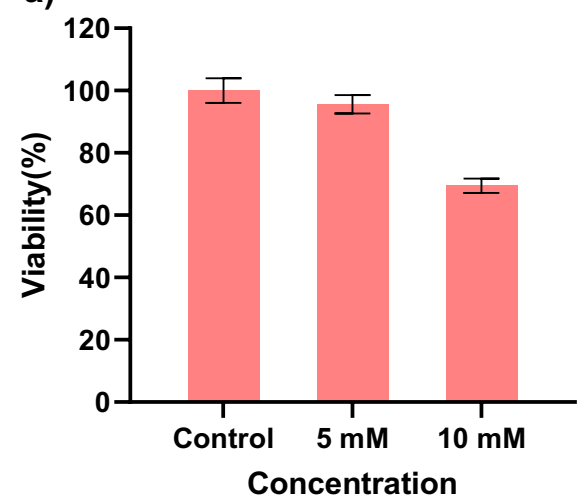

b)

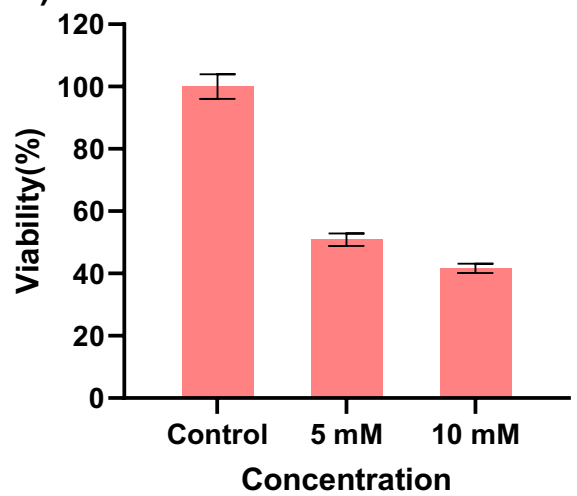

Figure S2. Cell viability after incubating with a) propionic acid, b) butyric acid for 48 hours.

Table S1. Post-thaw cell recovery of NIH-3T3 cells. ${ }^{a}$

\begin{tabular}{lcccr}
\hline & & \multicolumn{3}{c}{ Post-thaw recovery (\%) } \\
\cline { 3 - 5 } & & 0 -hr & \multicolumn{1}{c}{ 24-hr } & \multicolumn{1}{c}{48 -hr } \\
\hline SorbPr $_{2}(1)$ & $(10 \mathrm{mM})$ & $72.4 \pm 3.4$ & $65.2 \pm 2.2$ & $153.2 \pm 8.0$ \\
$\operatorname{MannPr}_{2}(2)$ & $(10 \mathrm{mM})$ & $84.1 \pm 3.3$ & $73.6 \pm 3.2$ & $184.1 \pm 14.2$ \\
$\operatorname{XyIPr}_{2}(3)$ & $(10 \mathrm{mM})$ & $52.1 \pm 4.8$ & $49.7 \pm 1.1$ & $90.0 \pm 4.3$ \\
$\operatorname{EryPr}_{2}(4)$ & $(10 \mathrm{mM})$ & $47.9 \pm 3.4$ & $42.6 \pm 2.6$ & $71.6 \pm 3.9$ \\
Mannitol & $(10 \mathrm{mM})$ & $24.1 \pm 1.8$ & $20.8 \pm 1.5$ & $41.5 \pm 3.0$ \\
Sorbitol & $(10 \mathrm{mM})$ & $32.8 \pm 3.2$ & $28.4 \pm 2.1$ & $50.8 \pm 3.5$ \\
Xylitol & $(10 \mathrm{mM})$ & $24.6 \pm 2.4$ & $22.1 \pm 2.1$ & $44.3 \pm 4.7$ \\
Erythritol & $(10 \mathrm{mM})$ & $33.5 \pm 2.7$ & $26.0 \pm 0.6$ & $42.3 \pm 1.2$ \\
Control-1 & & $33.2 \pm 3.6$ & $29.9 \pm 3.3$ & $52.7 \pm 4.0$ \\
Control-2 & & $84.5 \pm 3.8$ & $93.9 \pm 2.4$ & $196.4 \pm 5.7$ \\
\hline
\end{tabular}

${ }^{a}$ Recovery calculated by trypan blue exclusion. Each value obtained with 3 biological repeats and 3 technical replicates. Errors are \pm SEM. 


\section{Experimental Section}

Materials and general information. Dulbecco's high glucose modified Eagle's medium (DMEM) with HEPES (25 mM), Penicillin-Streptomycin-Glutamine (100X), PBS (phosphate buffered saline) and trypsin-EDTA $(0.25 \%)$ were obtained from Gibco. Calcein AM and ethidium Homodimer-1 (EthD-1) for live/dead fluorescence images were obtained from Thermo Fisher. All other chemicals were purchased from commercial sources and used as received. Silica gel for analytical thin layer chromatography (TLC) and column chromatography (mesh 230 400) were purchased from Sorbent Technologies Inc. $1 \mathrm{H}$ NMR spectra were recorded at $300 \mathrm{MHz}$ on Mercury-300 and $400 \mathrm{MHz}$ on INOVA-400. 13C NMR spectra were recorded at $75 \mathrm{MHz}$ on Mercury-300 spectrometers, and $101 \mathrm{MHz}$ on INOVA-400 at ambient temperature using $\mathrm{CDCl}_{3}$ or DMSO- $d_{6}$ as solvents (Cambridge Isotope Laboratories, Inc.). Chemical shifts are reported in parts per million (ppm) downfield from TMS (tetramethylsilane) or the deuterated solvents. Coupling constant in $1 \mathrm{H}-\mathrm{NMR}$ were expressed in Hertz (Hz). Regular mass spectra (MS-ESI) were recorded on a Thermo Finnegan LCQ Advantage MS spectrometer. High-resolution electrospray ionization mass spectra (HRMS-ESI) and Matrix-assisted laser desorption/ionization (HRMSMALDI) were recorded on a Bruker SolariX 12 T Fourier Transform Mass Spectrometer.

Cell culture. NIH/3T3 cells (ATCC CCL-92) were cultured in growth medium consisting of Dulbecco's Modified Eagle's Medium (DMEM, high glucose, with 25 mM HEPES) supplemented with $10 \%$ fetal bovine serum (FBS), 100 units/mL penicillin, $100 \mu \mathrm{g} / \mathrm{mL}$ streptomycin, $292 \mathrm{ng} / \mathrm{mL}$ L-glutamine in an incubator with $5 \% \mathrm{CO}_{2}$ and humidified environment at $37^{\circ} \mathrm{C}$. Cells were detached with $0.25 \%$ trypsin-EDTA, resuspended in growth medium, and counted prior to passaging.

Cytotoxicity. NIH/3T3 cells were seeded into 96-well plates (Fisher brand) at a density of 8,000 cells in $150 \mu \mathrm{L}$ growth medium per well. The cells were incubated for 24 hours at $37^{\circ} \mathrm{C}$ with $5 \%$ $\mathrm{CO}_{2}$. After 24 hours all medium was aspired one row at a time and treated with various concentrations of each compound ( $10 \mathrm{mM}, 5 \mathrm{mM}, 1 \mathrm{mM}, 0.5 \mathrm{mM}$ and $0.1 \mathrm{mM})$ or carboxylic acid / NaOH (10 mM / 5 mM, 5 mM / 2.5 mM). The control cells were treated with fresh medium only. The cells were then incubated again for 48 hours at $37^{\circ} \mathrm{C}$ with $5 \% \mathrm{CO}_{2}$. After incubation, all medium was aspired and replaced with fresh medium and $10 \%(\mathrm{v} / \mathrm{v}) \mathrm{CCK}-8$ reagent and returned to incubate at $37^{\circ} \mathrm{C}$ with $5 \% \mathrm{CO}_{2}$ for 2 hours. Cell viability was then calculated from the OD value read by a plate reader (Biotek Synergy $\mathrm{H} 1$ ) at wavelength of 450 $\mathrm{nm}$.

$$
\% \text { Cell Viability }=\frac{\text { OD treated cells }- \text { oD background }}{\text { OD control }- \text { OD background }} X 100
$$

The results of cell viability are calculated with average OD over 5 wells where no data is discarded and error is calculated with the standard deviation among those 5 wells. 
Preparation of sample solutions for incubation. Sample solutions with different compounds (diesters and sugar alcohols) were prepared by directly dissolving the compounds into culture medium (DMEM with 9\% FBS) and sterile-filtered through a PES $0.2 \mu \mathrm{m}$ syringe filter.

Incubation (for cell size measurement). $\mathrm{NIH} / 3 \mathrm{~T} 3$ cells were seeded into 6-well plates at a density of $5 \times 10^{4}$ cells $/ \mathrm{mL}(2 \mathrm{~mL} /$ well), allowed to adhere overnight and then incubated with different sample solutions $\left(2 \mathrm{~mL}\right.$ ) for 48 hours at $37{ }^{\circ} \mathrm{C}$ under $5 \% \mathrm{CO}_{2}$. Control cells were incubated with culture medium.

Cell size measurement. At the end of the incubation, the cells were rinsed with PBS $(1 \mathrm{~mL})$ and detached by $0.25 \%$ trypsin-EDTA $(1 \mathrm{~mL})$. The cells were pelleted $(200 \times \mathrm{g}, 5 \mathrm{~min})$ and resuspended in PBS $(1 \mathrm{~mL})$. The average cell size of the cell suspension was then obtained with a DeNovix Celldrop cell counter.

Incubation (for cryopreservation). NIH/3T3 cells were seeded into cell culture treated plates $(100 \mathrm{~mm})$ at a density of $2 \times 10^{4}$ cells $/ \mathrm{mL}(10 \mathrm{~mL} / \mathrm{plate})$, allowed to adhere overnight and then incubated with different sample solutions $\left(10 \mathrm{~mL}\right.$ ) for 48 hours at $37{ }^{\circ} \mathrm{C}$ under $5 \% \mathrm{CO}_{2}$. Control cells were incubated with growth medium.

Cryopreservation. At the end of the incubation, the cells were rinsed with PBS $(2 \mathrm{~mL})$ and detached using $0.25 \%$ trypsin-EDTA $(3 \mathrm{~mL})$. The cells were pelleted $(200 \times \mathrm{g}, 5 \mathrm{~min}$ ) and resuspended in growth medium with $400 \mathrm{mM}$ trehalose except for the control-2 group. For control-2 group, cells were resuspended in growth medium with 5\% DMSO (v/v). An aliquot of cells of each group was then removed for counting by a DeNovix Celldrop cell counter to obtain prefreeze number of viable cells. The remaining cell suspension was transferred into a $2 \mathrm{~mL}$ cryogenic vial. The vials were directly transferred to $-80^{\circ} \mathrm{C}$ freezer without controlling cooling rate and stored at $-80^{\circ} \mathrm{C}$ freezer for 3 days. To thaw, cryogenic vials were removed from $-80^{\circ} \mathrm{C}$ freezer and suspended in a $37{ }^{\circ} \mathrm{C}$ water bath until ice melt. To the contents of each vial $1 \mathrm{~mL}$ growth medium was added and centrifuged ( $200 \times \mathrm{g}, 5 \mathrm{~min})$. The supernatant was discarded and cell pellet was resuspended in $1 \mathrm{~mL}$ growth cell medium. An aliquot of cell suspension of each group was then removed for counting with a DeNovix Celldrop cell counter to obtain the number of viable cells at 0 -hr post-thaw. The remaining cell suspension was split equally and resuspended into two cell culture treated plates $(100 \mathrm{~mm})$ with $10 \mathrm{~mL}$ growth medium in each plate. The plates were then maintained for either 24 hours or 48 hours at $37{ }^{\circ} \mathrm{C}$ under $5 \% \mathrm{CO}_{2}$. After being cultured for either 24 hours or 48 hours, the cells were rinsed with PBS ( $2 \mathrm{~mL}$ ) and detached using $0.25 \%$ trypsin-EDTA ( $3 \mathrm{~mL}$ ). The cells were pelleted ( $200 \times \mathrm{g}, 5 \mathrm{~min}$ ) and resuspended in growth medium. The cell suspension was then analyzed by DeNovix Celldrop cell counter to obtain number of viable cells at either 24-hr or 48-hr post-thaw.

Trypan Blue Exclusion Assay. For all time points, a sample of cells was mixed 1:1 in 0.4\% trypan blue and counted using a DeNovix Celldrop. Cell recovery was calculated as the ratio of viable cells to the number of cells initially frozen. 


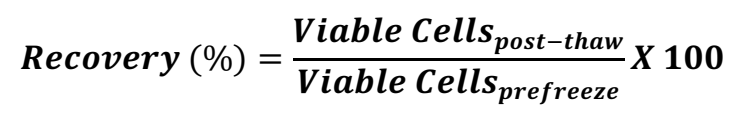

Fluorescence images capturing. $\mathrm{NIH} / 3 \mathrm{~T} 3$ cells were treated as the same as for cryopreservation experiment and were thawed in a $37^{\circ} \mathrm{C}$ water bath until ice melt. Cells in each vial were then pelleted ( $200 \times \mathrm{g}, 5 \mathrm{~min}$ ) and re-suspended in $1 \mathrm{~mL}$ fresh growth medium. For fluorescence images at 0 -hr post-thaw, $0.5 \mathrm{~mL}$ cell suspension was mixed with another $0.5 \mathrm{~mL}$ sterile PBS containing $4 \mu \mathrm{M}$ calcein-AM and $8 \mu \mathrm{M}$ ethidium homodimer-1 (EthD-1) in $1.5 \mathrm{~mL}$ Eppendorf tube. The tube was then incubated in a $\mathrm{CO}_{2}$ incubator at $37^{\circ} \mathrm{C}$ for $30 \mathrm{~min}$. The cells were pelleted $(200 \times g, 5 \mathrm{~min})$ and re-suspended in sterile PBS $(100 \mu \mathrm{L})$ after incubation. For fluorescence images at 24-hour post-thaw, cells after thawing were plated into 96 well plate and grown for 24 hours. Each well was washed with sterile PBS (100 $\mu \mathrm{L})$. Sterile PBS (200 $\mu \mathrm{L})$ containing $2 \mu \mathrm{M}$ calcein-AM and $4 \mu \mathrm{M}$ ethidium homodimer-1 (EthD-1) was then added to each well. The 96 -well plate was then incubated in a $\mathrm{CO}_{2}$ incubator at $37^{\circ} \mathrm{C}$ for $30 \mathrm{~min}$. Fluorescence images were captured at 509 and $580 \mathrm{~nm}$ on Axioplan 2 fluorescent microscope (Zeiss [Carl Zeiss], Thornwood, NY) with an Axiocam MRm camera (Zeiss). Axiovision 4 software (Zeiss) was used for image acquisition. Digital images were processed with ImageJ (https://imagej.nih.gov/ij/). 


\section{Synthesis and Characterization}

Scheme S1. Synthesis of diester SorbPr 2

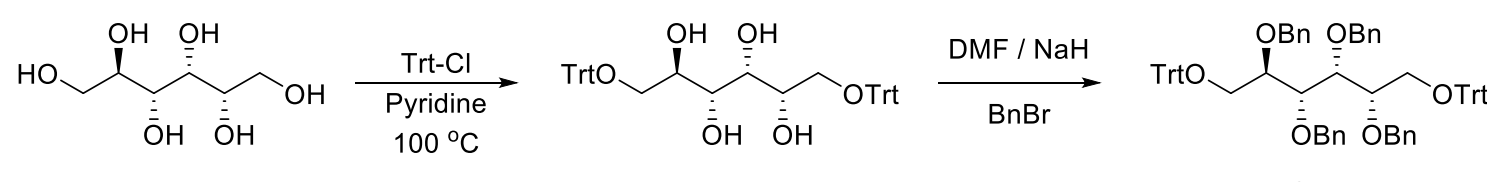

$$
\text { 5, } 88 \% \quad 6,75 \%
$$
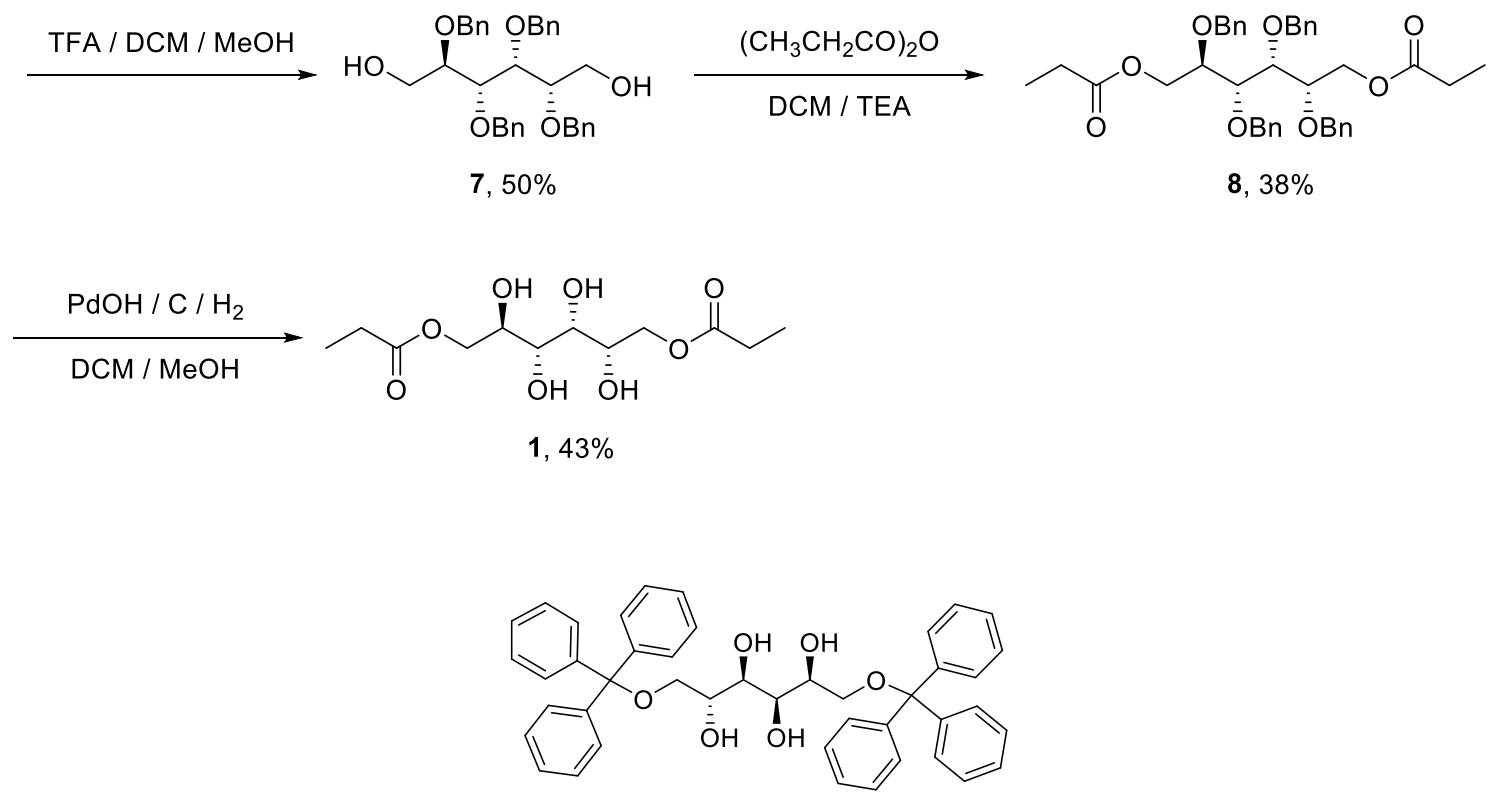

Compound 5. To a $500 \mathrm{~mL}$ round bottom, sorbitol $(5 \mathrm{~g}, 0.027 \mathrm{~mol})$ was added and dissolved in $60 \mathrm{~mL}$ pyridine. Triphenylmethyl chloride $(15.8 \mathrm{~g}, 0.058 \mathrm{~mol})$ was added to the flask, then the mixture was heated to $100^{\circ} \mathrm{C}$ overnight. The solvent was then removed under reduced pressure before $100 \mathrm{~mL} \mathrm{DCM}$ was added and then washed with $50 \mathrm{~mL}$ dilute $\mathrm{HCl}$ three times. The crude product was then purified via flash chromatography (hexane:ethyl acetate $=2: 1$ ) to give a white solid product (16.4 g, 88\% yield). ${ }^{1} \mathrm{H}$ NMR (400 MHz, DMSO- $\left.d_{6}\right) \delta 7.51-7.10(\mathrm{~m}, 17 \mathrm{H}), 4.89$ (dd, J $=41.3,5.0 \mathrm{~Hz}, 1 \mathrm{H}), 4.14(\mathrm{t}, J=6.7 \mathrm{~Hz}, 1 \mathrm{H}), 3.83-3.70(\mathrm{~m}, 2 \mathrm{H}), 3.32(\mathrm{dd}, J=16.1,9.5 \mathrm{~Hz}, 1 \mathrm{H})$, $3.11(\mathrm{dd}, J=9.3,2.7 \mathrm{~Hz}, 1 \mathrm{H}), 3.07-2.91(\mathrm{~m}, 2 \mathrm{H}) .{ }^{13} \mathrm{C}$ NMR (101 MHz, DMSO- $\left.d_{6}\right)$ 8150.0, 144.6, 144.5, 136.6, 128.9, 128.2, 128.1, 128.0, 127.3, 127.2, 124.3, 86.1, 72.7, 72.4, 70.7, 69.5, 66.6, 65.5. MS (ESI-TOF) m/z: [M + Na] $]^{+}$Calcd for $\mathrm{C}_{44} \mathrm{H}_{42} \mathrm{O}_{6} \mathrm{Na} 689.8$, found 689.5.

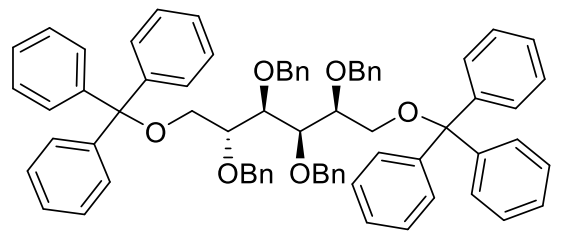


Compound 6. To a $500 \mathrm{~mL}$ round bottom compound 5 was added $(7.2 \mathrm{~g}, 0.0108 \mathrm{~mol})$ was dissolved in $100 \mathrm{~mL}$ DMF. Benzyl bromide $(6.4 \mathrm{~mL}, 0.0649 \mathrm{~mol})$ was added before the mixture was cooled to $0^{\circ} \mathrm{C}$. Sodium hydride $(2.5 \mathrm{~g}, 0.0649 \mathrm{~mol})$ was then added portion-wise and the reaction was spun overnight. Then water was added slowly and then extracted with $100 \mathrm{~mL}$ ethyl acetate 3 times. The organic layer was first dried under sodium sulfate before removing the solvent under reduced pressure before being purified via flash chromatography (hexane:ethyl acetate $=10: 1$ ) to yield a white solid ( $8.3 \mathrm{~g}, 75 \%$ yield). ${ }^{1} \mathrm{H}$ NMR (300 MHz, DMSO$\left.d_{6}\right) \delta 7.67-6.91(\mathrm{~m}, 46 \mathrm{H}), 4.70(\mathrm{~d}, J=11.8 \mathrm{~Hz}, 1 \mathrm{H}), 4.51(\mathrm{dt}, J=30.3,10.4 \mathrm{~Hz}, 2 \mathrm{H}), 4.08-3.77(\mathrm{~m}$, $3 \mathrm{H}), 3.36(\mathrm{~d}, J=8.4 \mathrm{~Hz}, 1 \mathrm{H}) .{ }^{13} \mathrm{C} \mathrm{NMR}\left(75 \mathrm{MHz}\right.$, DMSO- $\left.d_{6}\right) \delta 148.3,144.2,144.2,139.0,138.8$, $138.3,128.8,128.7,128.5,128.3,128.3,128.2,128.1,128.0,127.8,127.6,127.5,127.4,127.1$, 86.5, 86.3, 81.0, 79.8, 79.3, 79.0, 78.1, 74.1, 73.2, 72.7, 71.8. MS (ESI-TOF) m/z: [M + Na] $]^{+}$Calcd for $\mathrm{C}_{72} \mathrm{H}_{66} \mathrm{O}_{6} \mathrm{Na} 1050.3$, found 1049.8 .

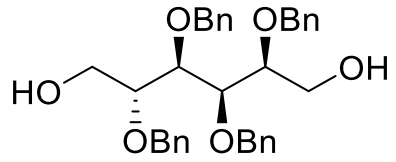

Compound 7. Compound 6 ( $3 \mathrm{~g}, 0.0029 \mathrm{~mol})$ was dissolved in $30 \mathrm{~mL} \mathrm{DCM}$ and $60 \mathrm{~mL}$ methanol. Trifluoroacetic acid (13. $5 \mathrm{~mL}$ ) was added and allowed to spin overnight. All solvent was removed under reduced pressure before purifying via flash chromatography (hexane:ethyl acetate $=1: 1)$ to yield a clear oil $(0.450 \mathrm{~g}, 50 \%) .{ }^{1} \mathrm{H}$ NMR $\left(300 \mathrm{MHz}, \mathrm{DMSO}-d_{6}\right) \delta 7.26(\mathrm{dt}, J=13.7$, $6.4 \mathrm{~Hz}, 9 \mathrm{H}), 4.71(\mathrm{~d}, J=11.6 \mathrm{~Hz}, 1 \mathrm{H}), 4.65-4.35(\mathrm{~m}, 3 \mathrm{H}), 3.96(\mathrm{~s}, 1 \mathrm{H}), 3.83(\mathrm{~d}, J=10.2 \mathrm{~Hz}, 1 \mathrm{H})$, 3.67 (q, $J=12.3,9.9 \mathrm{~Hz}, 2 \mathrm{H}) .{ }^{13} \mathrm{C}$ NMR $\left(75 \mathrm{MHz}, \mathrm{DMSO}-d_{6}\right) \delta 139.4,128.6,128.1,127.9,127.9$, 127.7. $\mathrm{MS}$ (ESI-TOF) $\mathrm{m} / \mathrm{z}$ : $\left[\mathrm{M}+\mathrm{H}^{+}\right.$] Calcd for $\mathrm{C}_{34} \mathrm{H}_{39} \mathrm{O}_{6} 543.7$, found 543.2.

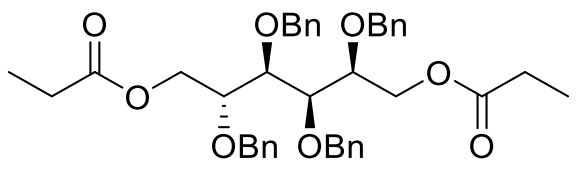

Compound 8. Compound 7 ( $0.150 \mathrm{~g}, 0.276 \mathrm{mmol}$ ) was dissolved in chloroform, then triethylamine $(0.770 \mathrm{~mL}, 5.52 \mathrm{mmol})$ was added. Propionic anhydride $(0.353 \mathrm{~mL}, 2.76 \mathrm{mmol})$ was added slowly then the reaction was spun overnight. The organic layer was then washed with water, followed by saturated potassium bicarbonate, and dilute $\mathrm{HCl}$. The organic layer was then dried over sodium sulfate before removing the solvent under reduced pressure. The crude product was then purified via flash chromatography to give a clear oil $(0.070 \mathrm{~g}, 38 \%) .{ }^{1} \mathrm{H}$ NMR $\left(400 \mathrm{MHz}, \mathrm{DMSO}-d_{6}\right) \delta 7.26(\mathrm{q}, J=7.2 \mathrm{~Hz}, 2 \mathrm{H}), 4.75-4.25(\mathrm{~m}, 11 \mathrm{H}), 4.15(\mathrm{~m}, 2 \mathrm{H}), 3.99-3.74$ $(\mathrm{m}, 4 \mathrm{H}), 2.24(\mathrm{~m}, 4 \mathrm{H}), 0.97(\mathrm{~m}, 6 \mathrm{H}) .{ }^{13} \mathrm{C} N M R\left(101 \mathrm{MHz}, \mathrm{DMSO}-d_{6}\right) \delta 173.9,173.9,138.8,138.7$, 128.7, 128.6, 128.3, 128.1, 128.0, 127.9, 104.5, 78.7, 78.4, 78.1, 77.4, 74.2, 73.8, 72.5, 71.6, 64.0, 63.3, 27.3, 27.2, 9.4. MS (ESI-TOF) m/z: [M + H+ Calcd for $\mathrm{C} 40 \mathrm{H} 4708$ 655.8, found 655.6. 
<smiles>CCC(=O)OC[C@H](O)[C@@H](O)[C@H](O)[C@H](O)COC(=O)CC</smiles>

Compound 1. Compound 8 (1 g, $0.0015 \mathrm{~mol})$ was dissolved in DCM $(20 \mathrm{~mL})$ and methanol (10 $\mathrm{mL}$ ), to which $\mathrm{Pd}(\mathrm{OH})_{2}(0.1 \mathrm{~g}, 50 \%$ water). The mixture was reacted under hydrogen (50 bar) for at least 6 hours until the starting materials disappeared and only one major spot showing on TLC plate. After removing the catalysis by filtration, the filtrate was concentrated under reduced pressure to remove the solvents. The crude product was purified via flash column chromatography (hexane:ethyl acetate $1: 1$ ) to give compound 1 as a white solid $(0.193 \mathrm{~g}, 43 \%)$. ${ }^{1} \mathrm{H}$ NMR $\left(400 \mathrm{MHz}\right.$, DMSO- $\left.d_{6}\right) \delta 4.93(\mathrm{~d}, J=4.9 \mathrm{~Hz}, 1 \mathrm{H}), 4.86(\mathrm{~d}, J=5.9 \mathrm{~Hz}, 1 \mathrm{H}), 4.47$ (dd, $J=21.2$, $6.7 \mathrm{~Hz}, 2 \mathrm{H}), 4.23(\mathrm{dd}, J=11.2,2.6 \mathrm{~Hz}, 1 \mathrm{H}), 4.12-3.92(\mathrm{~m}, 3 \mathrm{H}), 3.77(\mathrm{~m}, 1 \mathrm{H}), 3.67(\mathrm{~m}, 2 \mathrm{H}), 3.43$ $(\mathrm{m}, 1 \mathrm{H}), 2.31(\mathrm{~m}, 4 \mathrm{H}), 1.03(\mathrm{t}, J=7.5 \mathrm{~Hz}, 6 \mathrm{H}) .{ }^{13} \mathrm{C}$ NMR $\left(101 \mathrm{MHz}\right.$, DMSO-d $\left.d_{6}\right) \delta 174.3,174.2,71.5$, 71.0, 69.5, 68.9, 66.8, 66.1, 27.3, 9.4. HRMS (ESI-TOF) m/z: [M + Na+] Calcd for $\mathrm{C} 12 \mathrm{H} 22 \mathrm{NaO}^{+}$ 317.1207 , found 317.1214 .

Compounds 1a, 2, 2a, 3, and $\mathbf{4}$ were synthesized based on similar procedures used for preparing compound 1.<smiles>CCCC(=O)OC[C@H](O)[C@@H](O)[C@H](O)[C@H](O)COC(=O)CCC</smiles>

Compound 1a. ${ }^{1} \mathrm{H}$ NMR (400 MHz, DMSO- $\left.d_{6}\right) \delta 4.92(\mathrm{~d}, J=5.0 \mathrm{~Hz}, 1 \mathrm{H}), 4.85(\mathrm{~d}, J=6.0 \mathrm{~Hz}, 1 \mathrm{H})$, $4.47(\mathrm{dd}, J=19.2,6.8 \mathrm{~Hz}, 2 \mathrm{H}), 4.23(\mathrm{dd}, J=11.3,2.6 \mathrm{~Hz}, 1 \mathrm{H}), 4.15-3.90(\mathrm{~m}, 3 \mathrm{H}), 3.76(\mathrm{dd}, J=$ 7.6, 4.2 Hz, 1H), $3.67(q, J=5.3,3.9 \mathrm{~Hz}, 2 \mathrm{H}), 3.47-3.36(\mathrm{~m}, 1 \mathrm{H}), 2.27(\mathrm{~m}, 4 \mathrm{H}), 1.55(\mathrm{~m}, 4 \mathrm{H}), 0.88$ $(\mathrm{td}, J=7.4,1.4 \mathrm{~Hz}, 6 \mathrm{H}) .{ }^{13} \mathrm{C}$ NMR $\left(101 \mathrm{MHz}\right.$, DMSO- $\left.d_{6}\right) \delta 173.4,173.3,71.5,71.1,69.5,68.9,66.7$, 66.0, 35.9, 35.8, 18.4, 13.9. HRMS (ESI-TOF) m/z: [M + Na+] Calcd for $\mathrm{C} 14 \mathrm{H} 26 \mathrm{NaO}^{+} 345.1520$, found 345.1533 .<smiles>CCC(=O)OC[C@H](O)[C@@H](O)[C@H](O)[C@H](O)COC(=O)CC</smiles>

Compound 2. ${ }^{1} \mathrm{H}$ NMR (400 MHz, DMSO-d $\left.d_{6}\right) \delta 4.54(\mathrm{~s}, 3 \mathrm{H}), 4.28(\mathrm{dd}, J=11.2,2.3 \mathrm{~Hz}, 2 \mathrm{H}$ ), 3.97 (dd, $J=11.2,6.5 \mathrm{~Hz}, 2 \mathrm{H}$ ), $3.67(\mathrm{~m}, 2 \mathrm{H}), 3.57(\mathrm{~d}, J=9.1 \mathrm{~Hz}, 2 \mathrm{H}), 2.31$ (q, $J=7.5 \mathrm{~Hz}, 4 \mathrm{H}), 1.03(\mathrm{t}, J=$ $7.5 \mathrm{~Hz}, 6 \mathrm{H}) .{ }^{13} \mathrm{C}$ NMR $\left(101 \mathrm{MHz}\right.$, DMSO- $\left.d_{6}\right) \delta 174.3,69.5,68.6,67.3,27.3,9.5$. HRMS (ESI-TOF) $\mathrm{m} / \mathrm{z}:\left[\mathrm{M}+\mathrm{Na}^{+}\right]$Calcd for $\mathrm{C} 12 \mathrm{H} 22 \mathrm{NaO}^{+} 317.1207$, found 317.1216. 
<smiles>CCCC(=O)OC[C@H](O)[C@@H](O)[C@H](O)[C@H](O)COC(=O)CCC</smiles>

Compound 2a. ${ }^{1} \mathrm{H}$ NMR $\left(400 \mathrm{MHz}\right.$, DMSO- $\left.d_{6}\right) \delta 4.80(\mathrm{~d}, J=6.1 \mathrm{~Hz}, 2 \mathrm{H}), 4.36-4.25(\mathrm{~m}, 4 \mathrm{H}), 3.96$ $(\mathrm{dd}, J=11.2,6.6 \mathrm{~Hz}, 2 \mathrm{H}), 3.66(\mathrm{~m}, 2 \mathrm{H}), 3.56(\mathrm{t}, J=8.5 \mathrm{~Hz}, 2 \mathrm{H}), 3.34(\mathrm{~s}, 1 \mathrm{H}), 2.28(\mathrm{t}, J=7.3 \mathrm{~Hz}, 4 \mathrm{H})$, $1.55(\mathrm{~m}, 4 \mathrm{H}), 0.88(\mathrm{t}, J=7.4 \mathrm{~Hz}, 6 \mathrm{H}) .{ }^{13} \mathrm{C}$ NMR $\left(101 \mathrm{MHz}, \mathrm{DMSO}-d_{6}\right) \delta 173.5,69.5,68.6,67.3,35.9$, 18.4, 13.9. HRMS (ESI-TOF) m/z: [M + Na+] Calcd for $\mathrm{C} 14 \mathrm{H} 26 \mathrm{NaO}^{+} 345.1520$, found 345.1538 .<smiles>CCC(=O)OC[C@H](O)[C@@H](O)[C@H](O)COC(=O)CC</smiles>

Compound 3. ${ }^{1} \mathrm{H}$ NMR $\left(400 \mathrm{MHz}, \mathrm{DMSO}-d_{6}\right) \delta 4.83(\mathrm{~d}, J=5.8 \mathrm{~Hz}, 2 \mathrm{H}), 4.67(\mathrm{~d}, J=6.4 \mathrm{~Hz}, 1 \mathrm{H}), 4.09$ - $3.94(\mathrm{~m}, 4 \mathrm{H}), 3.72(\mathrm{~m}, 2 \mathrm{H}), 3.42-3.30(\mathrm{~m}, 3 \mathrm{H}), 2.27(\mathrm{q}, J=7.5 \mathrm{~Hz}, 4 \mathrm{H}), 0.99(\mathrm{t}, J=7.6 \mathrm{~Hz}, 6 \mathrm{H})$. ${ }^{13} \mathrm{C}$ NMR $\left(101 \mathrm{MHz}\right.$, DMSO- $\left.d_{6}\right) \delta 174.1,71.2,69.3,66.0,27.2,9.4$. HRMS (ESI-TOF) m/z: [M + $\left.\mathrm{Na}^{+}\right]$ Calcd for $\mathrm{C} 11 \mathrm{H} 2 \mathrm{ONaO} 7^{+} 287.1101$, found 287.1110 .<smiles>CCC(=O)OC[C@H](O)[C@H](O)COC(=O)CC</smiles>

Compound 4. ${ }^{1} \mathrm{H}$ NMR (400 MHz, DMSO- $\left.d_{6}\right) \delta 5.08(\mathrm{~d}, J=5.1 \mathrm{~Hz}, 2 \mathrm{H}), 4.25-4.15(\mathrm{~m}, 2 \mathrm{H}), 3.96$ (m, 2H), $3.60-3.52(\mathrm{~m}, 2 \mathrm{H}), 2.32(\mathrm{q}, J=7.5 \mathrm{~Hz}, 4 \mathrm{H}), 1.03(\mathrm{t}, J=7.5 \mathrm{~Hz}, 6 \mathrm{H}) .{ }^{13} \mathrm{C} \mathrm{NMR}(101 \mathrm{MHz}$, DMSO- $\left.d_{6}\right) \delta 174.2,69.6,66.3,27.2,9.4$. HRMS (ESI-TOF) m/z: [M + $\left.\mathrm{Na}^{+}\right]$Calcd for $\mathrm{C} 10 \mathrm{H} 18 \mathrm{NaO}^{+}$ 257.0996, found 257.1011 . 


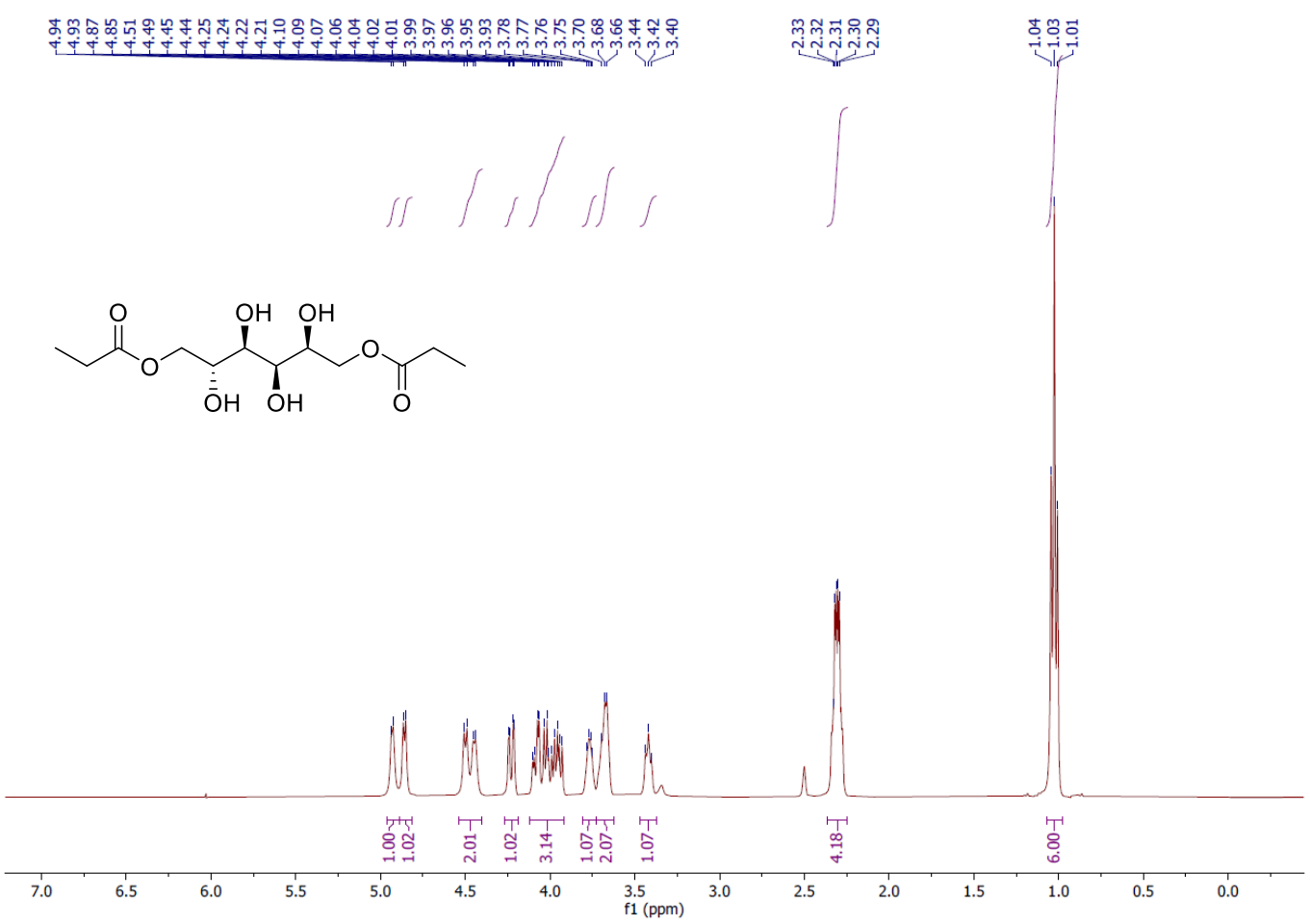

Figure S3. ${ }^{1} \mathrm{H}$ NMR spectrum of 1 in DMSO- $d_{6}$ at $25^{\circ} \mathrm{C}(400 \mathrm{MHz})$

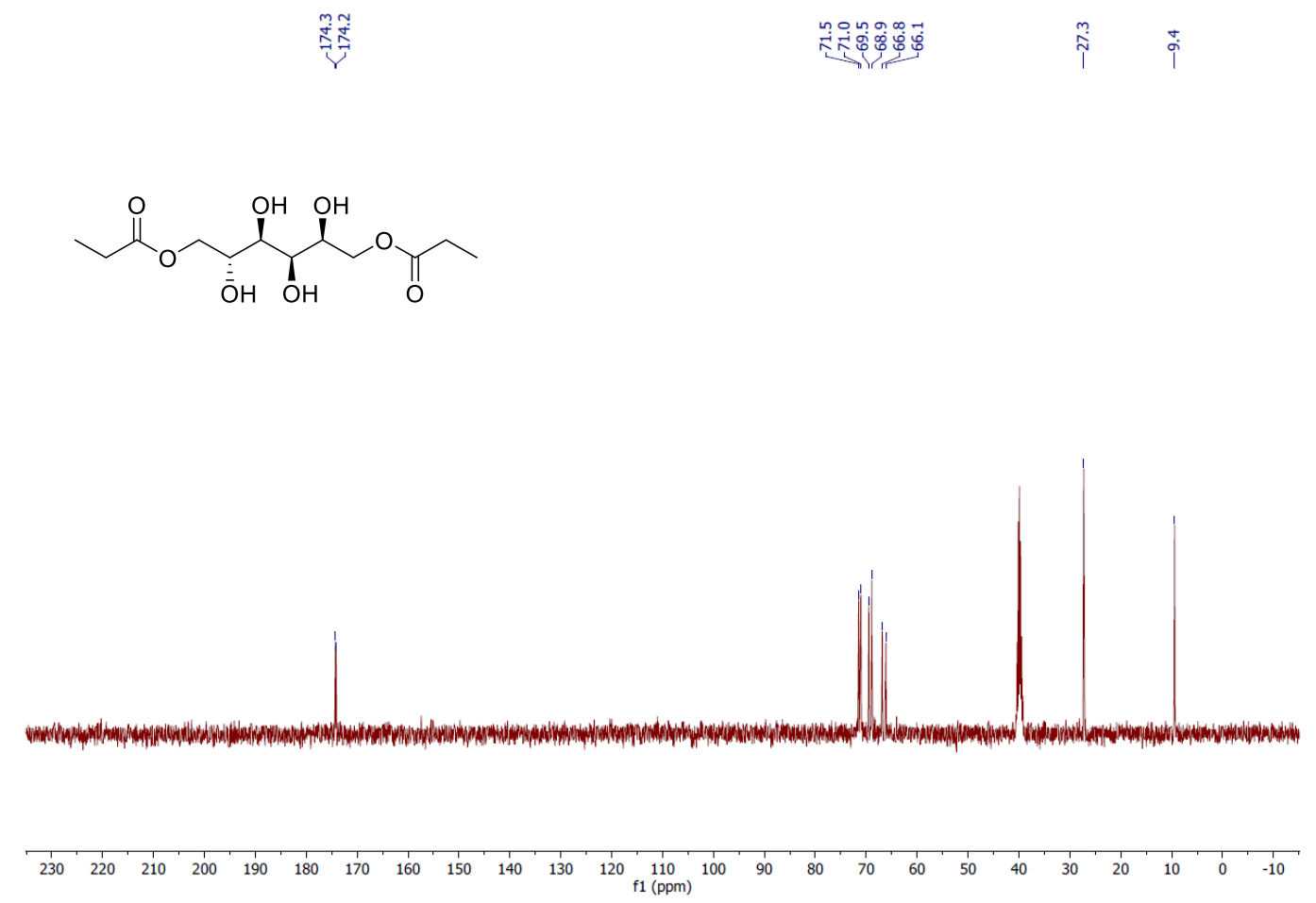

Figure S4. ${ }^{13} \mathrm{C}$ NMR spectrum of 1 in DMSO- $d_{6}$ at $25{ }^{\circ} \mathrm{C}(101 \mathrm{MHz})$ 


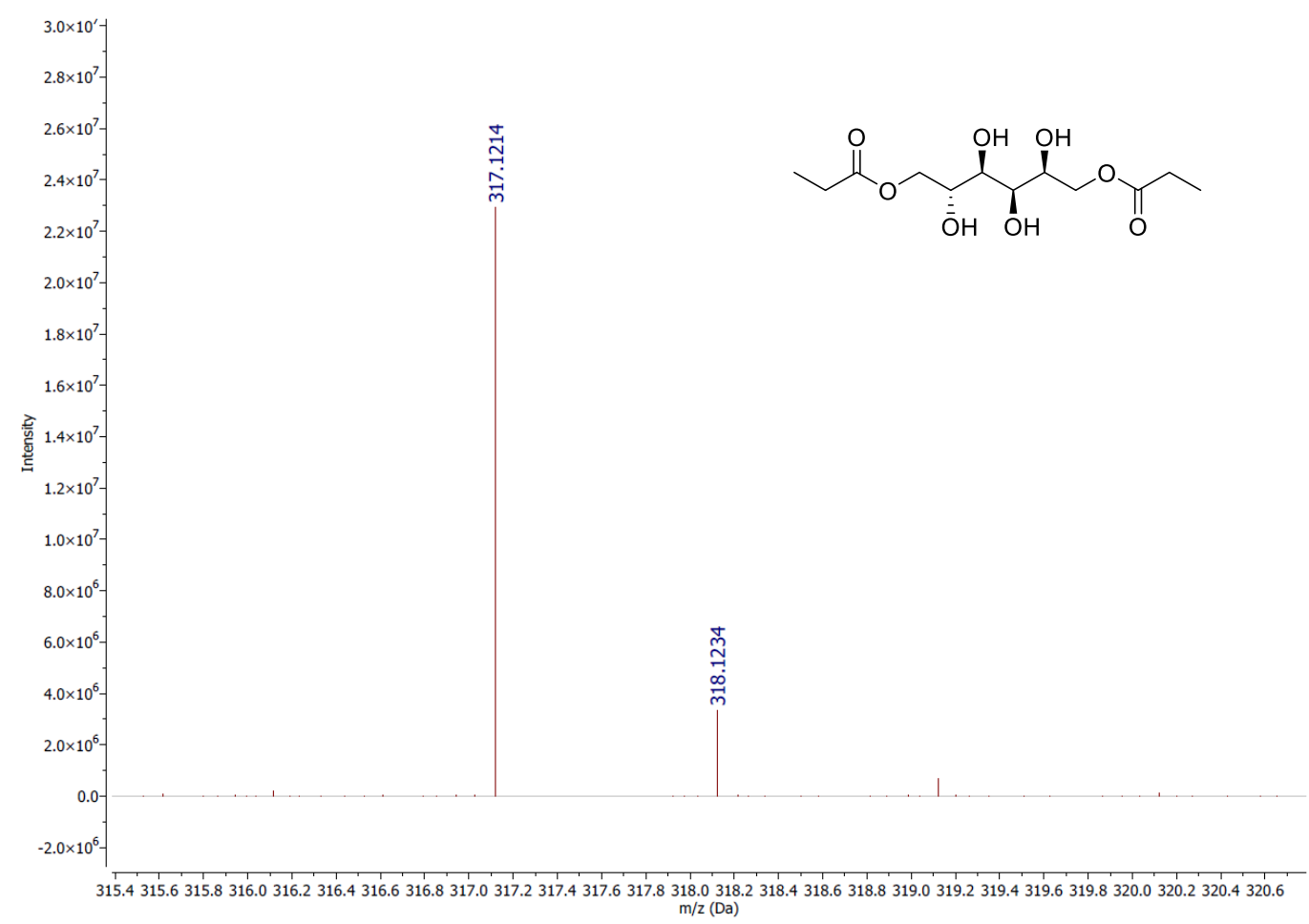

Figure S5. HRMS spectrum of 1.

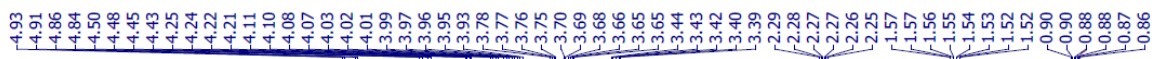
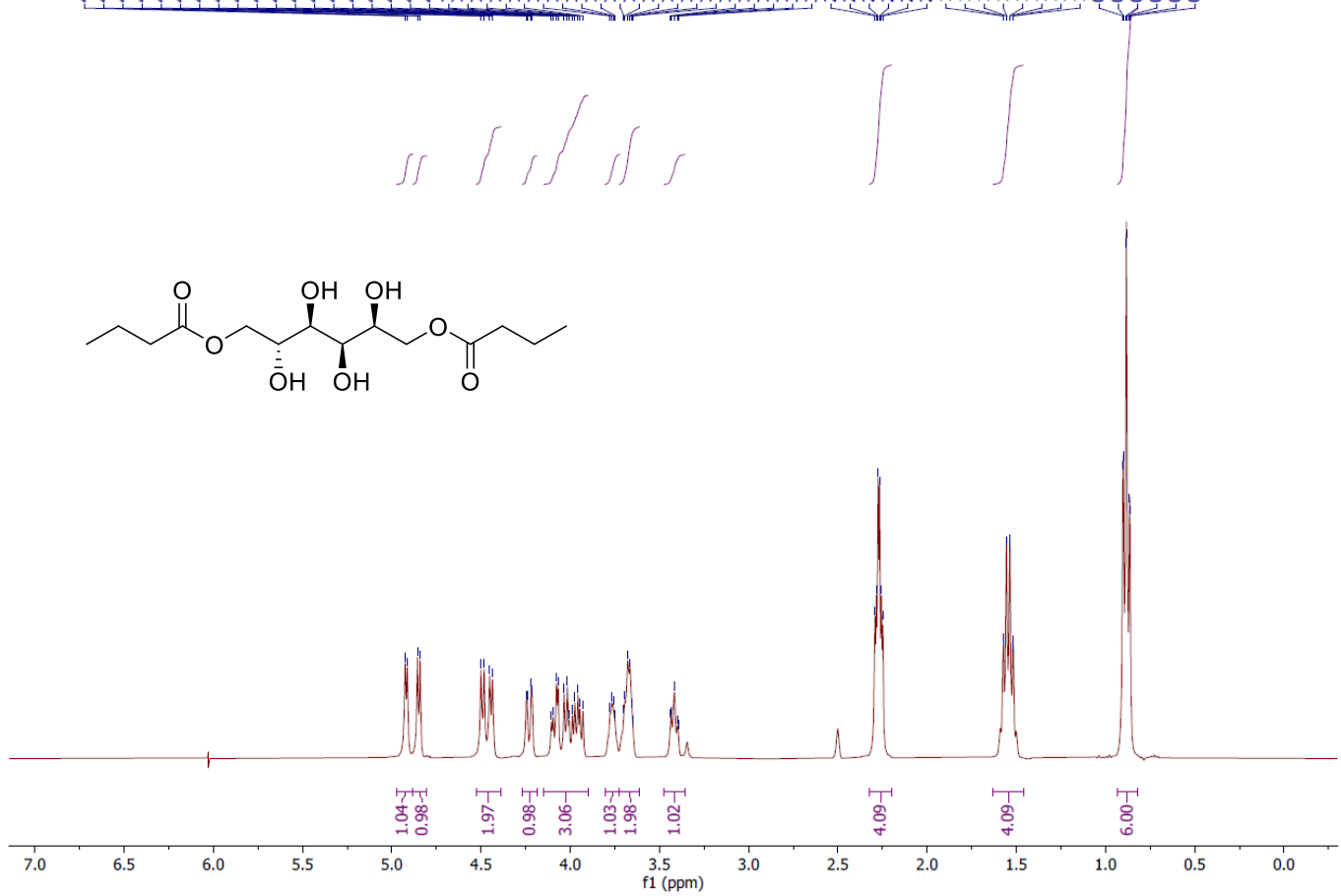

Figure S6. ${ }^{1} \mathrm{H}$ NMR spectrum of $1 \mathrm{a}$ in DMSO- $d_{6}$ at $25^{\circ} \mathrm{C}(400 \mathrm{MHz})$ 


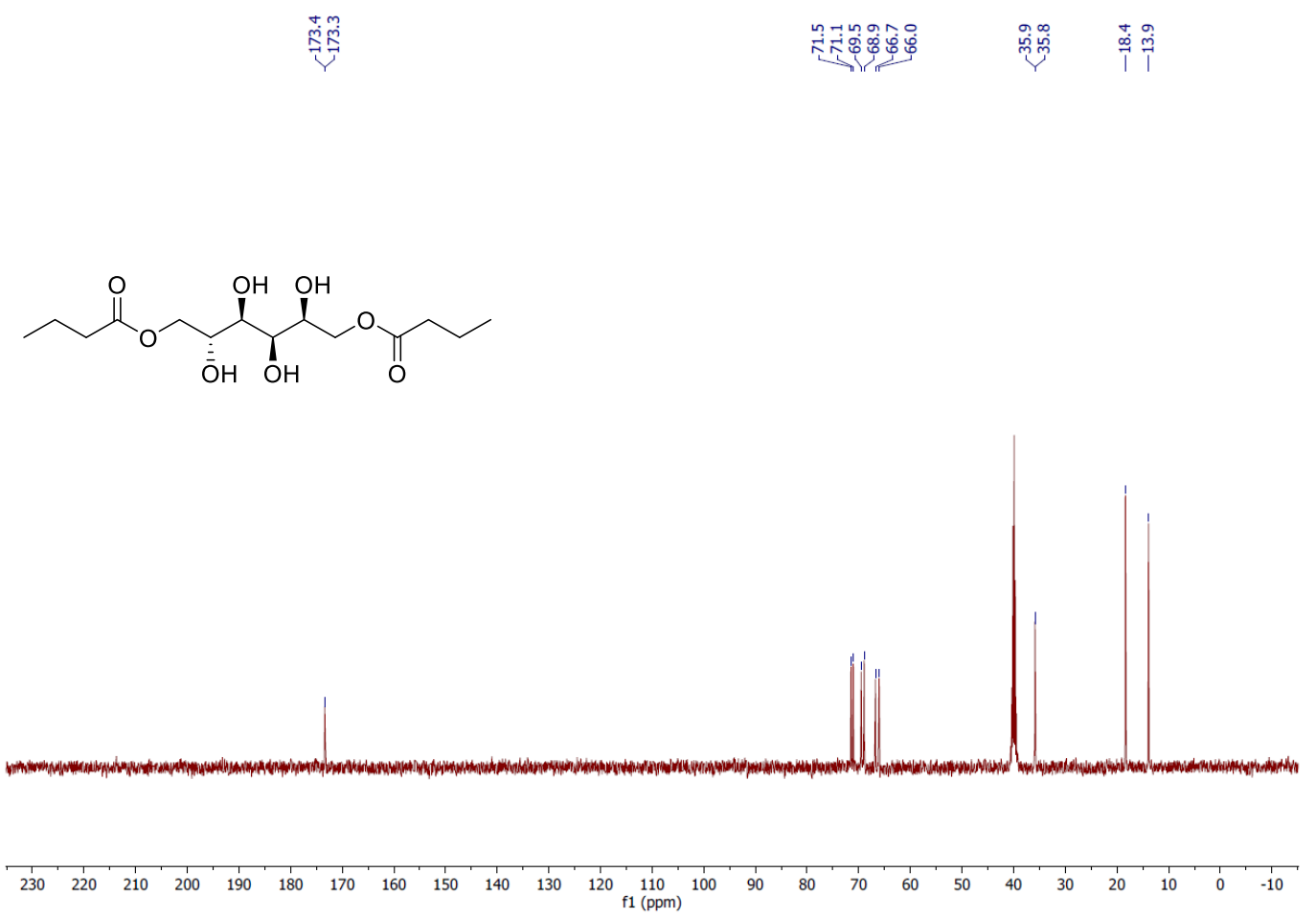

Figure S7. ${ }^{13} \mathrm{C}$ NMR spectrum of $1 \mathrm{a}$ in DMSO- $d_{6}$ at $25{ }^{\circ} \mathrm{C}(101 \mathrm{MHz})$

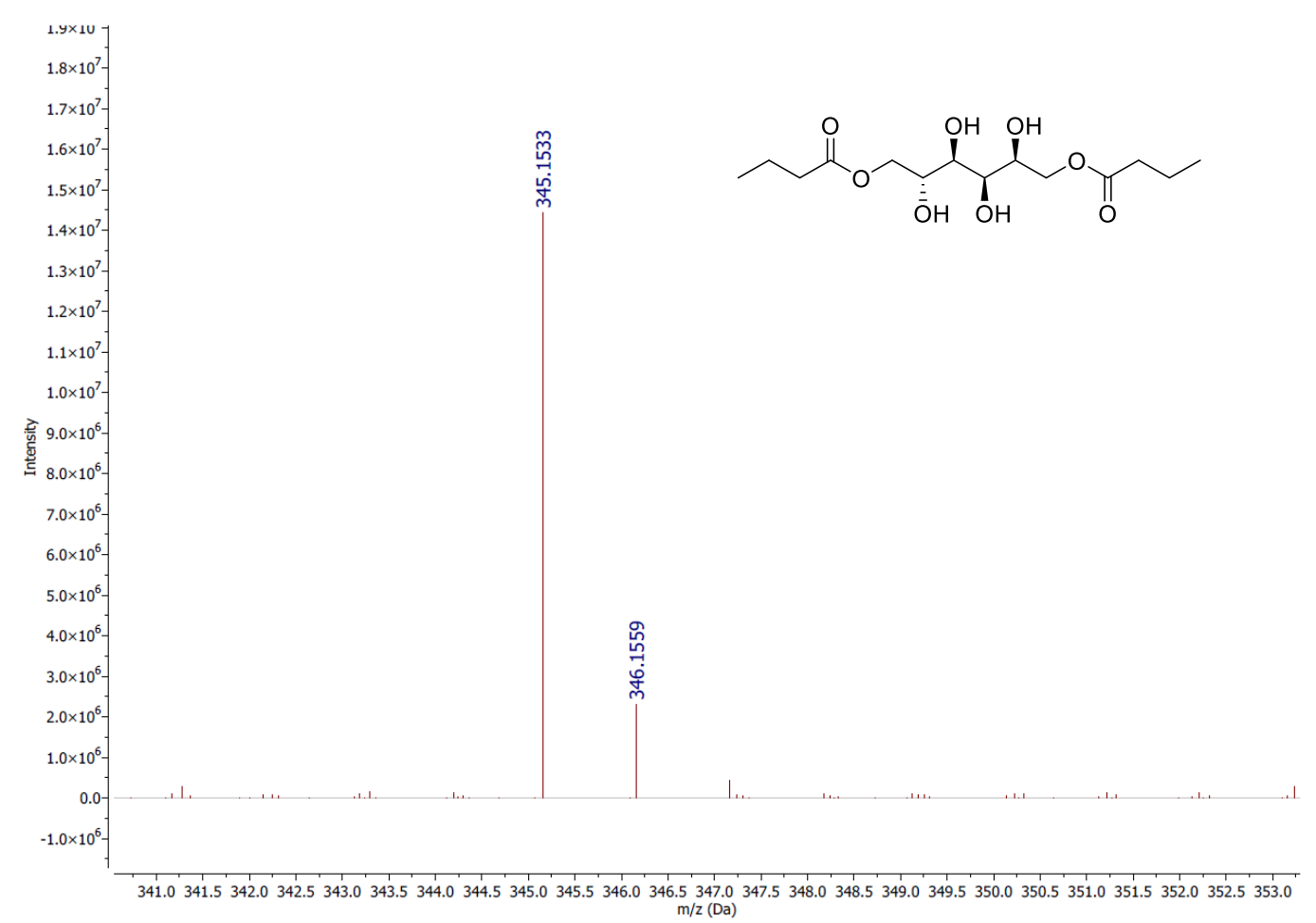

Figure S8. HRMS spectrum of $\mathbf{1 a .}$ 


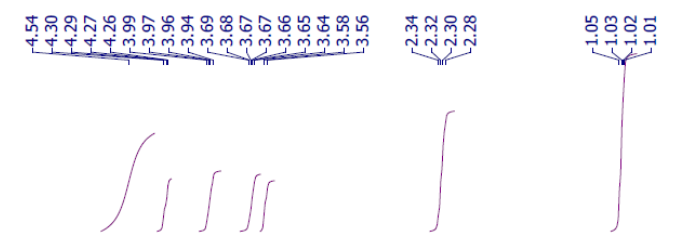

$\underbrace{\mathrm{O}}_{\mathrm{O} H \mathrm{OH}}$

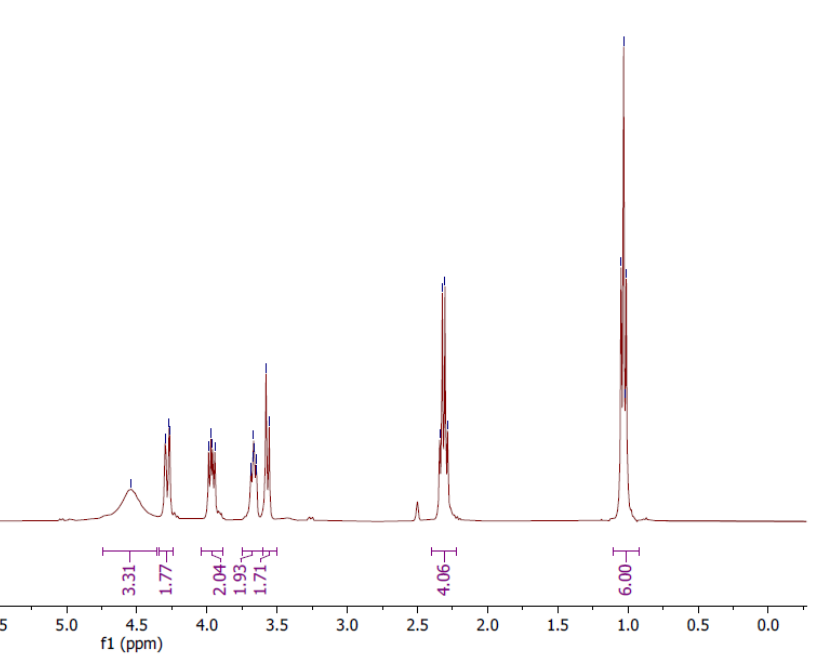

Figure S9. ${ }^{1} \mathrm{H}$ NMR spectrum of 2 in DMSO- $d_{6}$ at $25^{\circ} \mathrm{C}(400 \mathrm{MHz})$
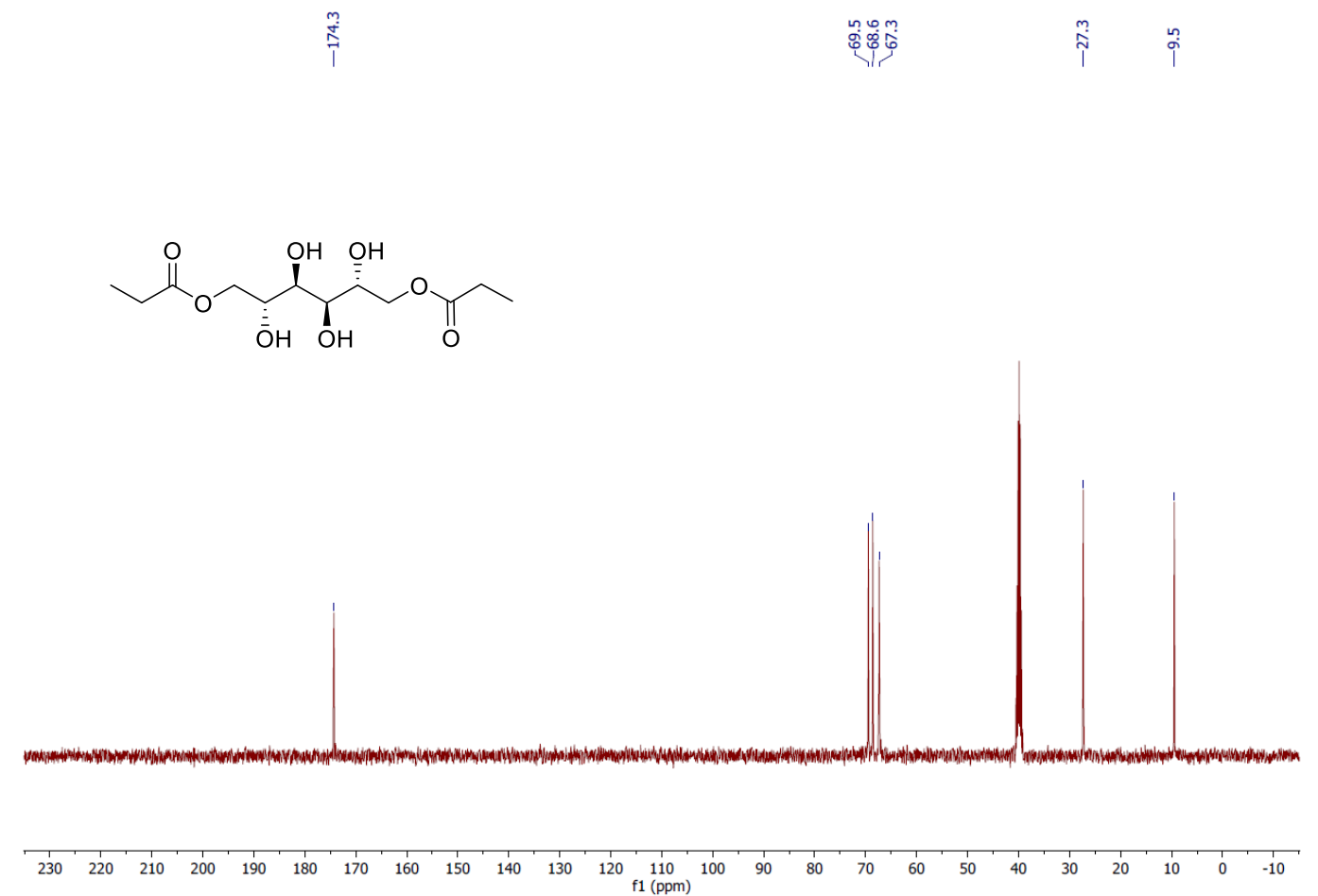

Figure S10. ${ }^{13} \mathrm{C}$ NMR spectrum of 2 in DMSO- $d_{6}$ at $25^{\circ} \mathrm{C}(101 \mathrm{MHz})$ 


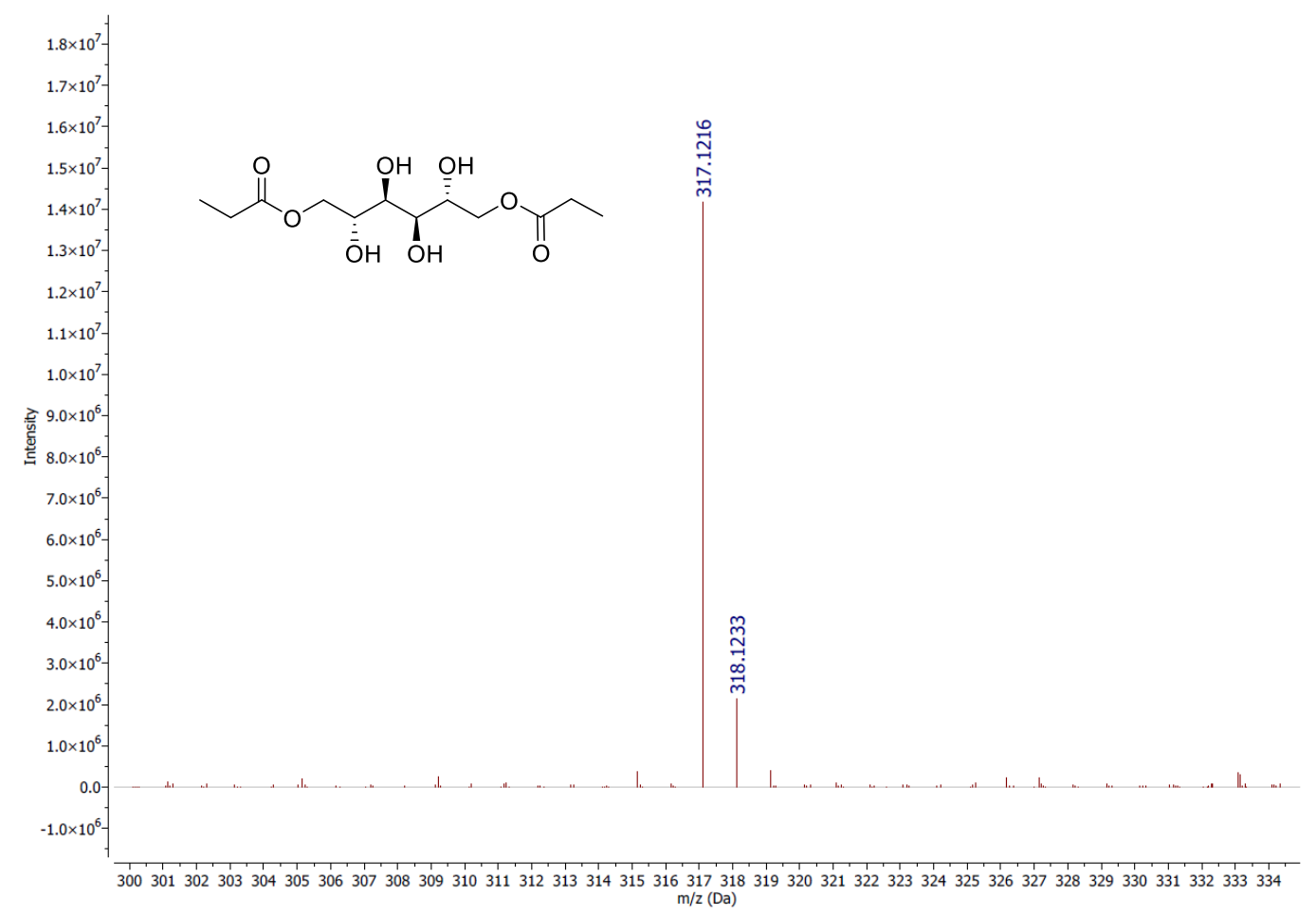

Figure S11. HRMS spectrum of 2.

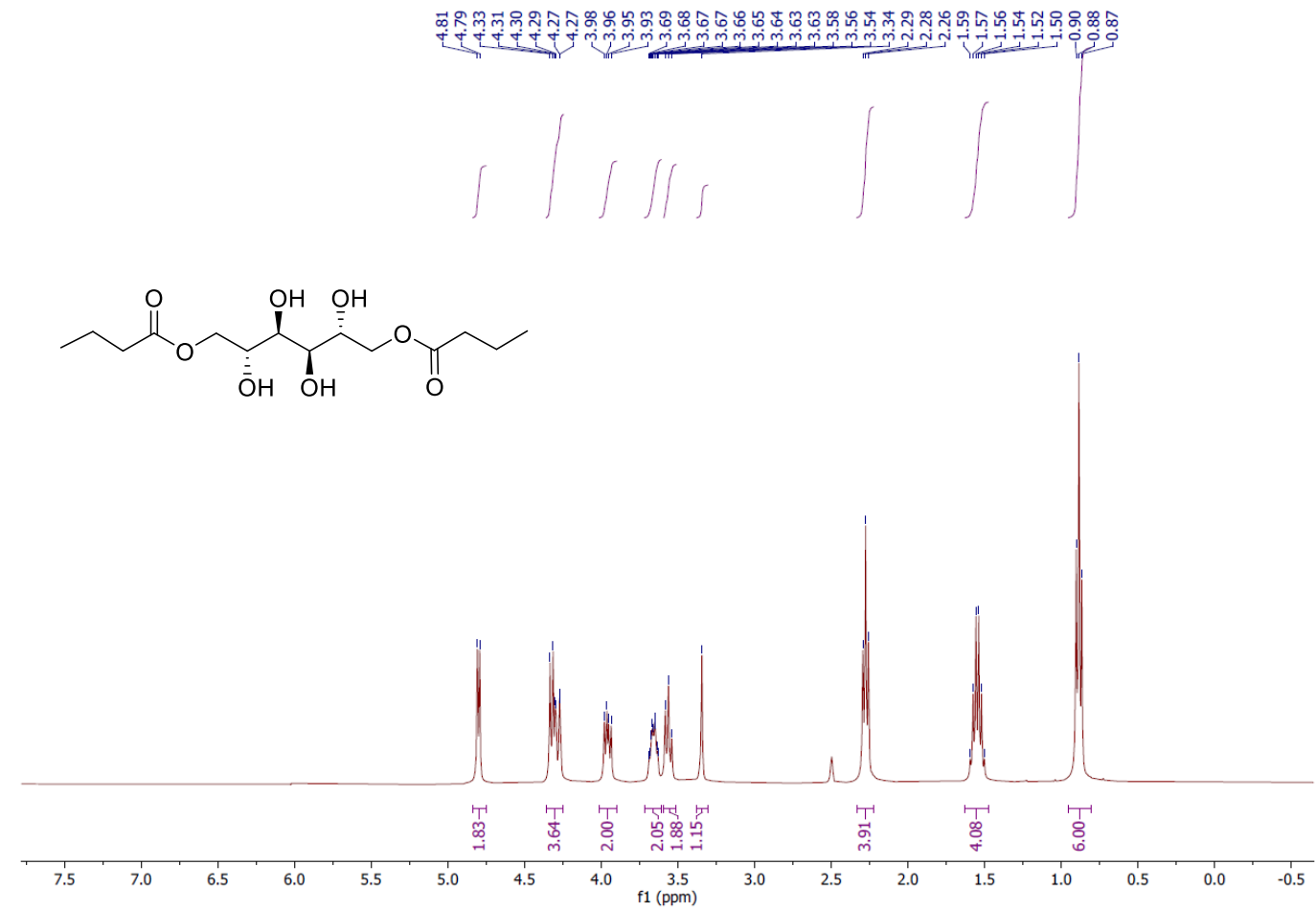

Figure S12. ${ }^{1} \mathrm{H}$ NMR spectrum of $2 \mathrm{a}$ in DMSO- $d_{6}$ at $25^{\circ} \mathrm{C}(400 \mathrm{MHz})$ 

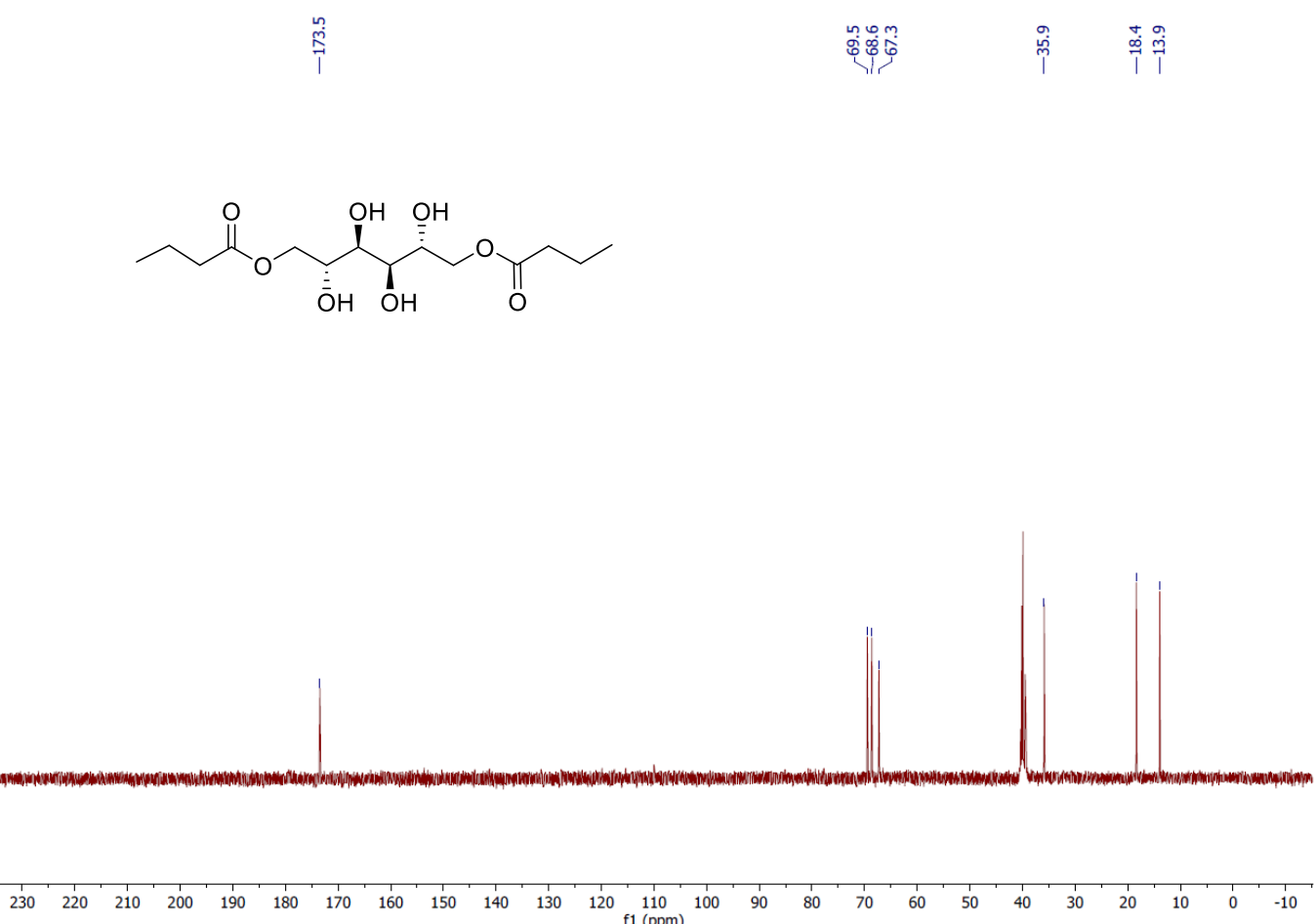

Figure $\mathbf{S 1 3 .}{ }^{13} \mathrm{C}$ NMR spectrum of $2 \mathrm{a}$ in DMSO- $d_{6}$ at $25{ }^{\circ} \mathrm{C}(101 \mathrm{MHz})$

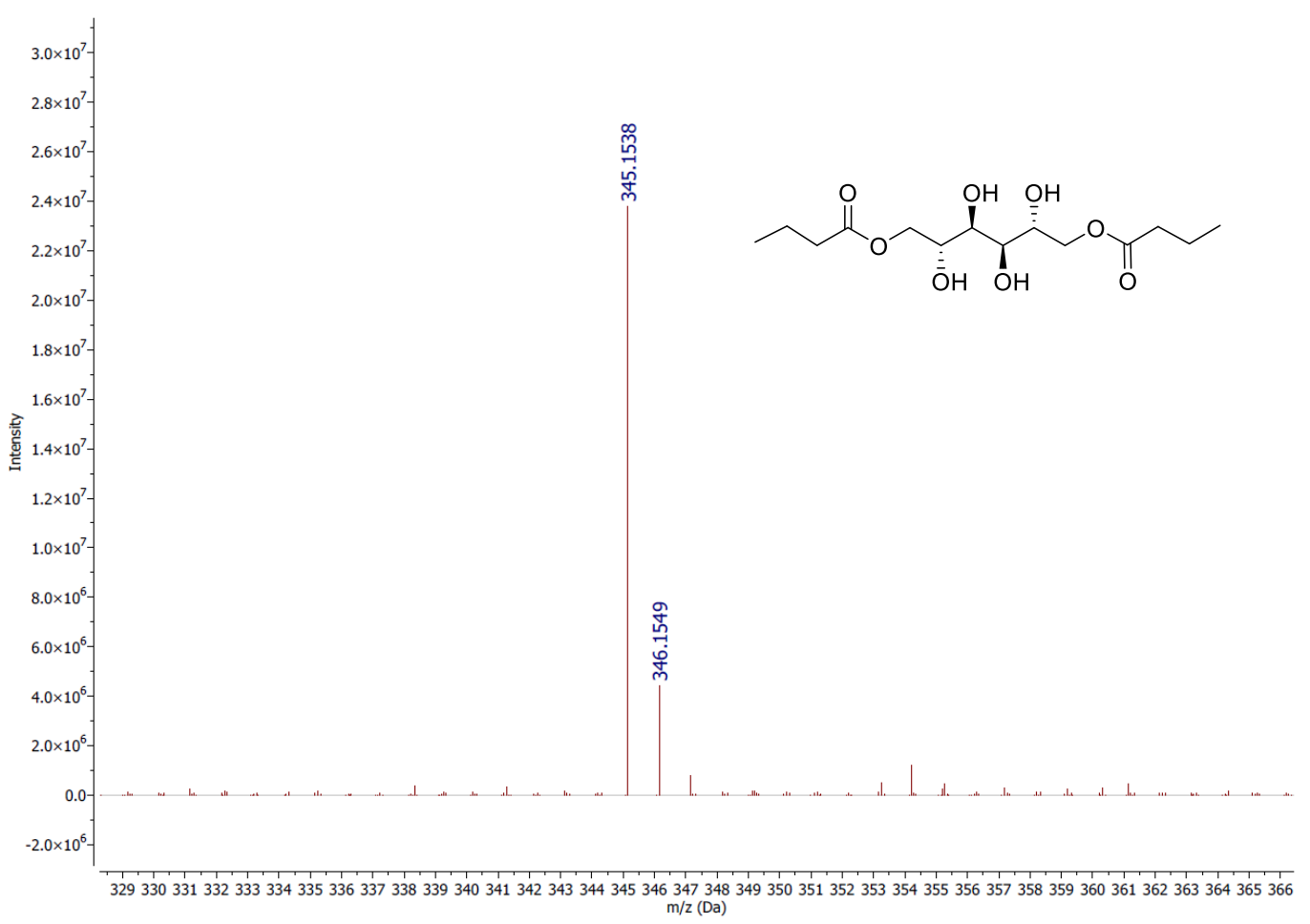

Figure S14. HRMS spectrum of $\mathbf{2 a}$. 


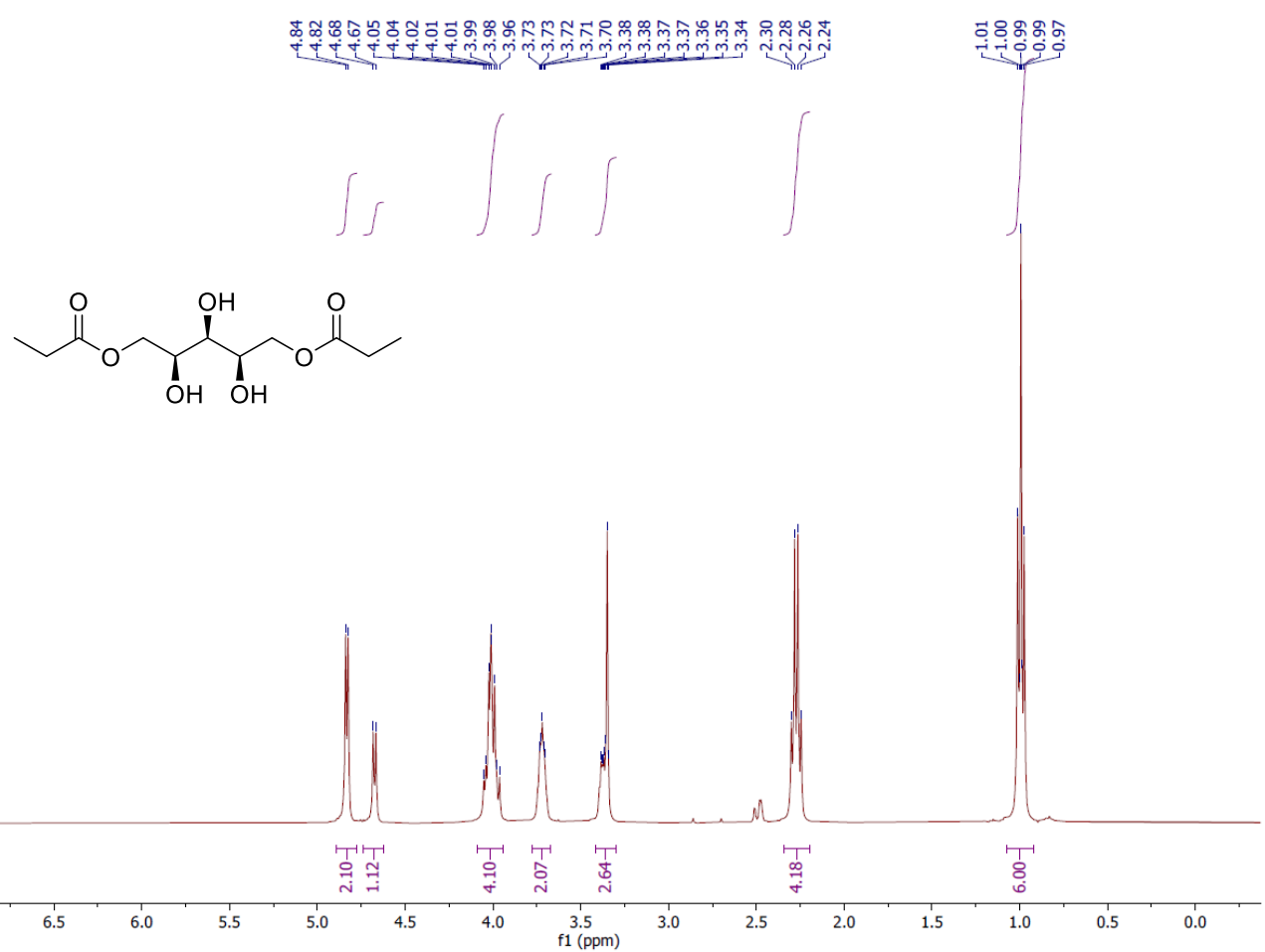

Figure S15. ${ }^{1} \mathrm{H}$ NMR spectrum of 3 in DMSO- $d_{6}$ at $25^{\circ} \mathrm{C}(400 \mathrm{MHz})$
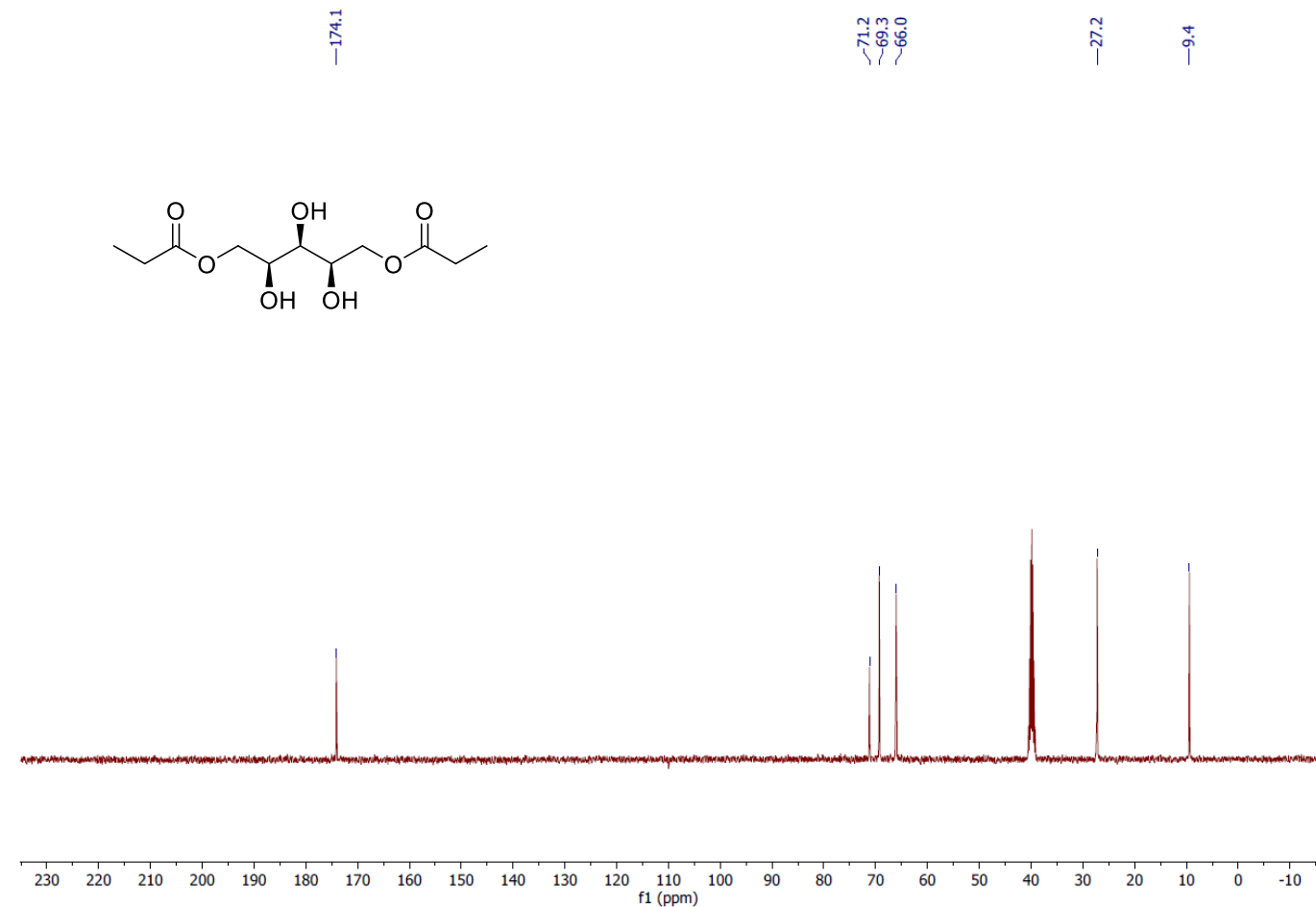

Figure S16. ${ }^{13} \mathrm{C}$ NMR spectrum of 3 in DMSO- $d_{6}$ at $25^{\circ} \mathrm{C}(101 \mathrm{MHz})$ 


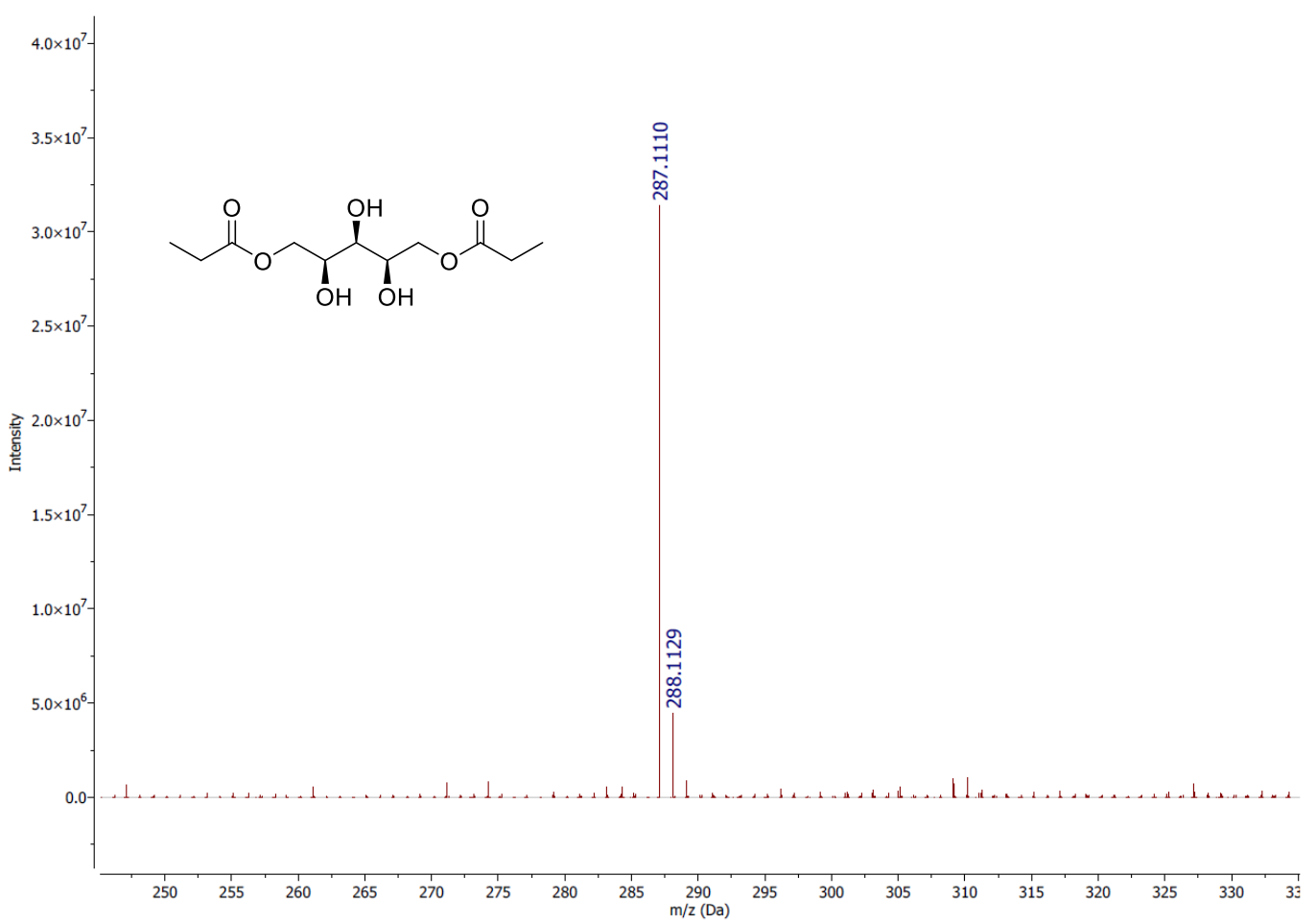

Figure S17. HRMS spectrum of 3.

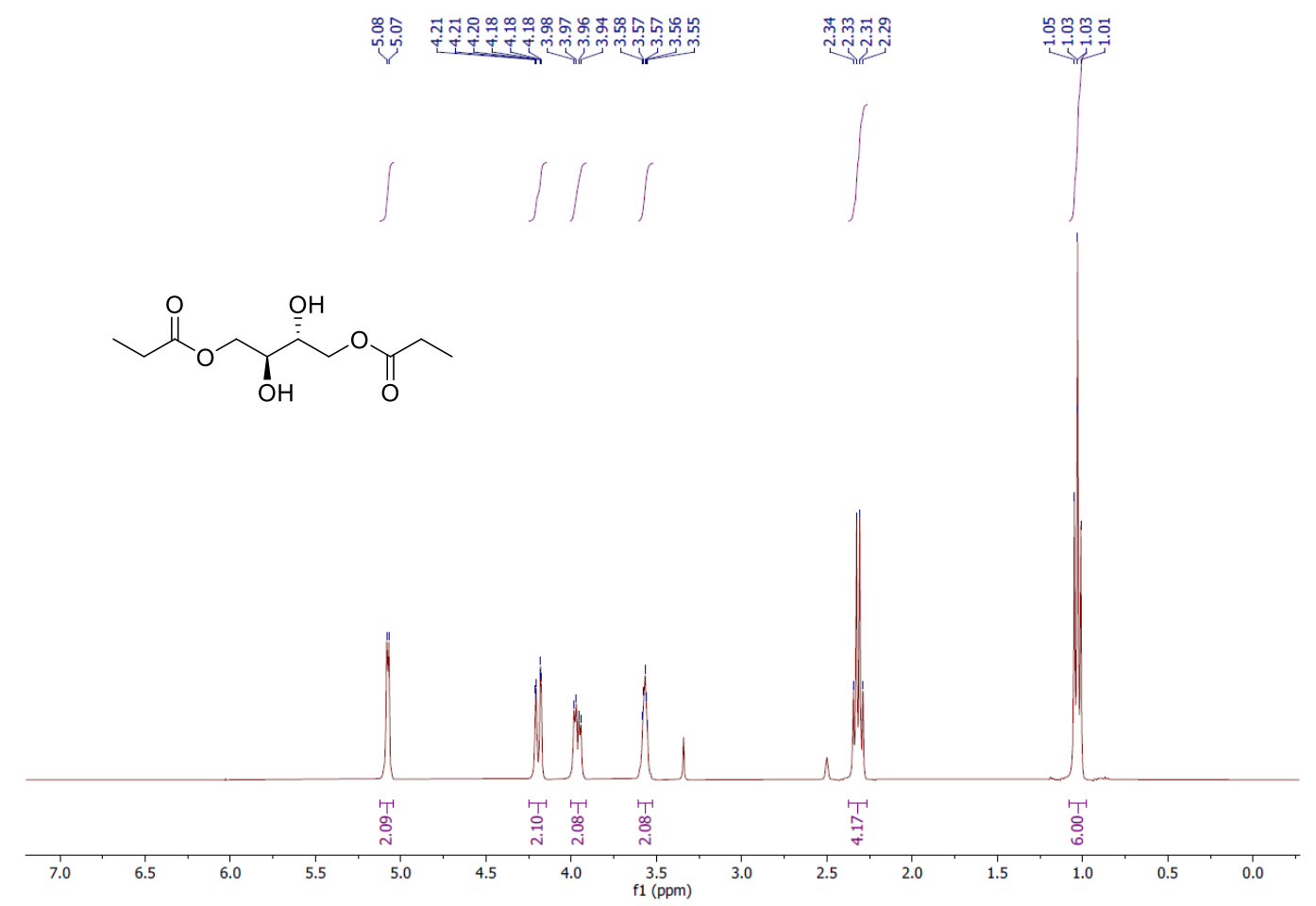

Figure S18. ${ }^{1} \mathrm{H}$ NMR spectrum of 4 in DMSO- $d_{6}$ at $25^{\circ} \mathrm{C}(400 \mathrm{MHz})$ 

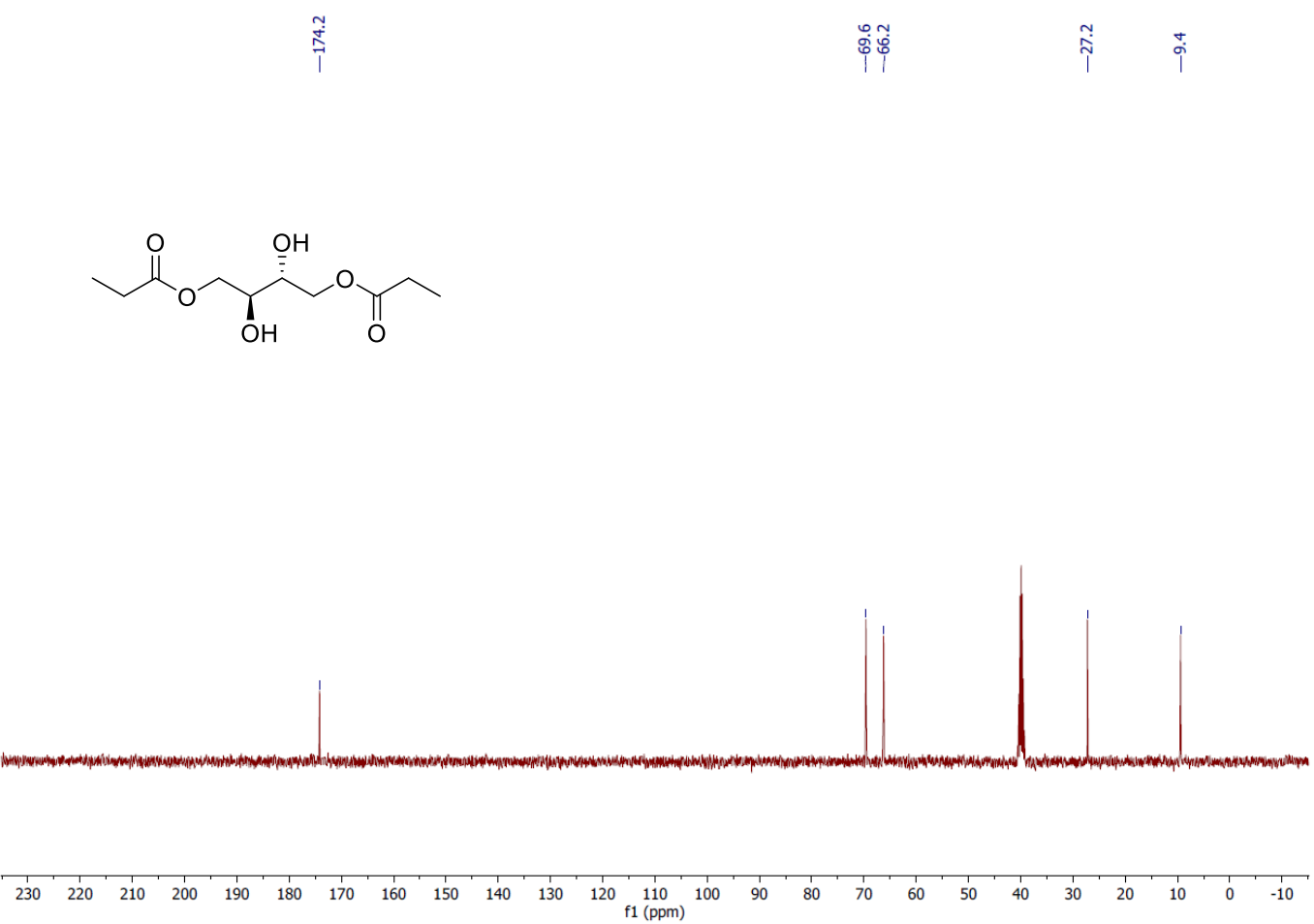

Figure S19. ${ }^{13} \mathrm{C}$ NMR spectrum of 4 in DMSO- $d_{6}$ at $25^{\circ} \mathrm{C}(101 \mathrm{MHz})$

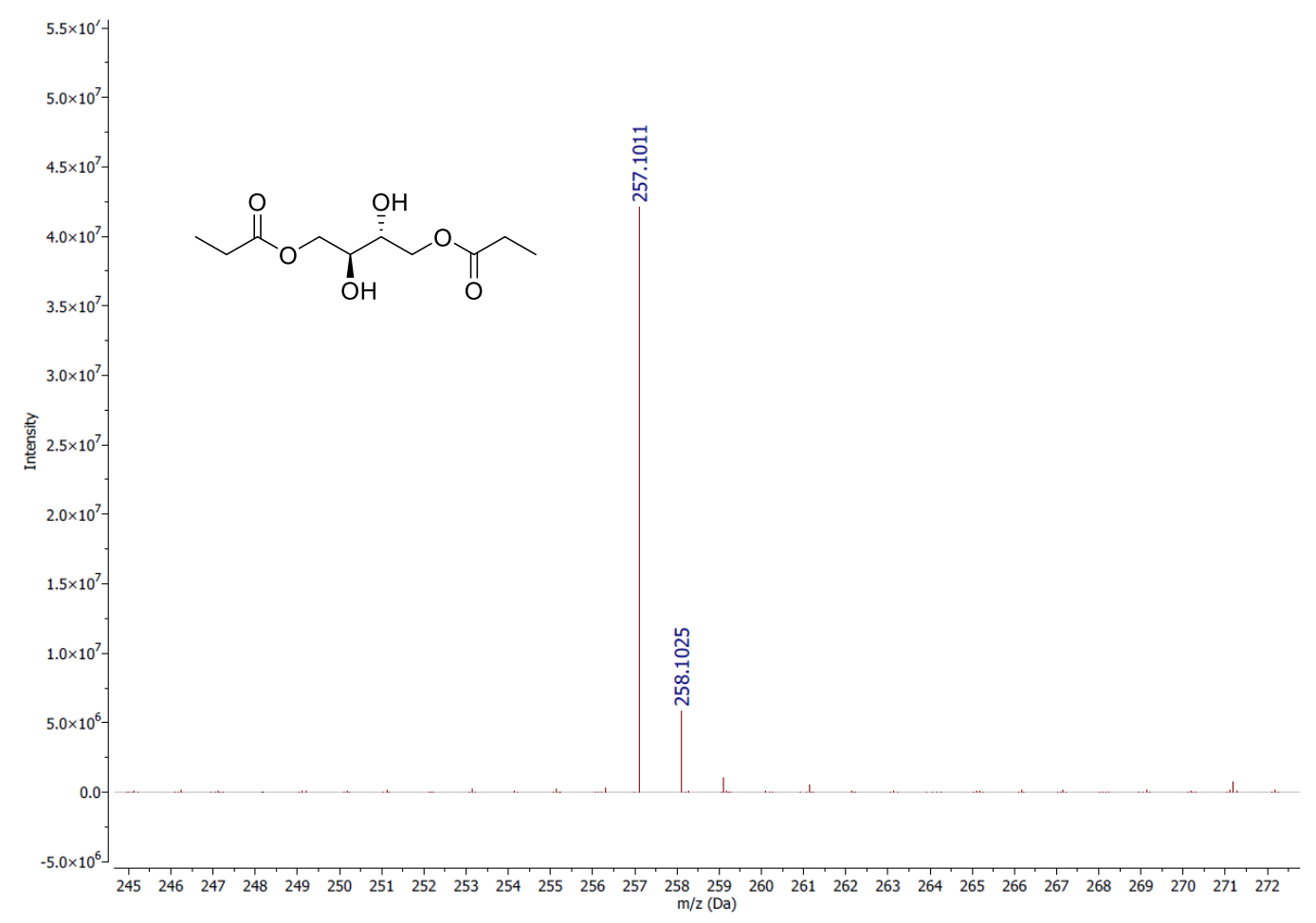

Figure S20. HRMS spectrum of 4. 